\title{
Mechanisms of different response to ionizing irradiation in isogenic head and neck cancer cell lines
}

\author{
Vesna Todorovic ${ }^{1}$, Ajda Prevc ${ }^{1}$, Martina Niksic Zakelj”, Monika Savarin ${ }^{1}$, Andreja Brozic ${ }^{2}$, Blaz Groselj
} Primoz Strojan ${ }^{3,4}$, Maja Cemazar ${ }^{1,5}$ and Gregor Sersa ${ }^{1,6^{*}}$ (I)

\begin{abstract}
Background: Treatment options for recurrent head and neck tumours in the previously irradiated area are limited, including re-irradiation due to radioresistance of the recurrent tumour and previous dose received by surrounding normal tissues. As an in vitro model to study radioresistance mechanisms, isogenic cells with different radiosensitivity can be used. However, they are not readily available. Therefore, our objective was to establish and characterize radioresistant isogenic human pharyngeal squamous carcinoma cells and to evaluate early radiation response in isogenic parental, radioresistant and radiosensitive cells.
\end{abstract}

Methods: Radioresistant cells were derived from parental FaDu cells by repeated exposure to ionizing radiation. Radiosensitivity of the established isogenic radioresistant FaDu-RR cells was evaluated by clonogenic assay and compared to isogenic parental FaDu and radiosensitive 2A3 cells. Additional phenotypic characterization of these isogenic cells with different radiosensitivity included evaluation of chemosensitivity, cell proliferation, cell cycle, radiation-induced apoptosis, resolution of DNA double-strand breaks, and DNA damage and repair signalling gene expression before and after irradiation.

Results: In the newly established radioresistant cells in response to $5 \mathrm{~Gy}$ irradiation, we observed no alteration in cell cycle regulation, but delayed induction and enhanced resolution of DNA double-strand breaks, lower induction of apoptosis, and pronounced over-expression of DNA damage signalling genes in comparison to parental cells. On the other hand, radiosensitive $2 \mathrm{~A} 3$ cells were arrested in $\mathrm{G}_{2} / \mathrm{M}$-phase in response to $5 \mathrm{~Gy}$ irradiation, had a prominent accumulation of and slower resolution of DNA double-strand breaks, and no change in DNA damage signalling genes expression.

Conclusions: We concluded that the emergence of the radioresistance in the established radioresistant isogenic cells can be at least partially attributed to the enhanced DNA double-strand break repair, altered expression of DNA damage signalling and repair genes. On the other hand, in radiosensitive isogenic cells the reduced ability to repair a high number of induced DNA double-strand breaks and no transcriptional response in DNA damage signalling genes indicate on a lack of adaptive response to irradiation. Altogether, our results confirmed that these isogenic cells with different radiosensitivity are an appropriate model to study the mechanisms of radioresistance.

Keywords: Head and neck cancer, Squamous cell carcinoma, Radioresistance, Radiotherapy, Cancer recurrence, Chemoresistance, Radiotherapy, Gene expression profiles, DNA damage, DNA repair

\footnotetext{
* Correspondence: gsersa@onko-i.si

${ }^{1}$ Department of Experimental Oncology, Institute of Oncology Ljubljana,

Ljubljana, Slovenia

${ }^{6}$ University of Ljubljana, Faculty of Health Sciences, Ljubljana, Slovenia

Full list of author information is available at the end of the article
}

(c) The Author(s). 2019 Open Access This article is distributed under the terms of the Creative Commons Attribution 4.0 International License (http://creativecommons.org/licenses/by/4.0/), which permits unrestricted use, distribution, and

reproduction in any medium, provided you give appropriate credit to the original author(s) and the source, provide a link to the Creative Commons license, and indicate if changes were made. The Creative Commons Public Domain Dedication waiver (http://creativecommons.org/publicdomain/zero/1.0/) applies to the data made available in this article, unless otherwise stated. 


\section{Background}

Head and neck cancers are a heterogeneous group of tumours arising in multiple anatomic sub sites in the head and neck region, which are histologically mainly squamous cell carcinomas (SCCs) [1]. The major risk factor for the SCCs arising in the oral cavity, oropharynx, hypopharynx, and larynx is habitual exposure to tobacco and/or alcohol consumption, while human papillomavirus (HPV) infection is associated with oropharyngeal tumours [2]. Different etiology of head and neck SCC also reflects in different tumour biology. Namely, HPVpositive oropharyngeal tumours and cell lines are more sensitive to radiotherapy and chemotherapy treatment than HPV-negative [3-5]. Most commonly, a combination of surgery and (chemo) radiotherapy or upfront chemoradiotherapy is used for the treatment of nonmetastatic head and neck SCC, as they result in a better effect than surgery or radiotherapy alone [6].

Despite the advances made in the management of head and neck SCC, a high locoregional recurrence or second primary cancer remain a serious problem in the previously treated area $[7,8]$. Management of the recurrent or second primary SCC is often limited to palliative radiotherapy or systemic therapy, with a high risk of normal tissue toxicity, impaired quality of life and poor outcome [7].

The observed radioresistant tumour phenotype is a combination of numerous factors: disease clinical features, e.g. tumour stage and volume, microenvironment features, e.g. hypoxia, and intrinsic cellular features, e.g. enhanced DNA repair, modulation of cell cycle progression, free radical and reactive oxygen species (ROS) scavenging [9]. These intrinsic radioprotective mechanisms give a survival advantage to radioresistant cells, leading to treatment failure.

To improve therapeutic efficacy, it is crucial to understand and elucidate the underlying mechanisms of intrinsic cellular radioresistance. Isogenic cell lines with different radiosensitivity can be established from parental cell lines by repeated exposure to radiation and/or carcinogens [10]. Generally, these isogenic pairs include parental cells, and the established cells with a more radioresistant phenotype, while isogenic cells with a more radiosensitive phenotype are rarely commercially available $[9,11]$.

The aims of this study were to establish radioresistant isogenic cells from parental head and neck SCC cells, by repeated exposure to radiation, and to identify the differences in the irradiation response of the newly established radioresistant cells in comparison to isogenic parental and radiosensitive cells. Furthermore, the radio- and chemosensitivity, cell proliferation, cell cycle, induction and resolution of DNA double-strand breaks (DSBs) in parental, radioresistant and radiosensitive isogenic cells were evaluated. Additionally, the DNA damage signalling gene expression in these isogenic cells before and after irradiation, with a specific focus on the early response to irradiation, was elucidated.

\section{Methods}

\section{Cell lines and cell culture conditions}

Human pharyngeal SCC cell line FaDu (ATCC, HTB-43) was grown in Advanced Dulbecco's Modified Eagle Medium (DMEM, Gibco, Thermo Fisher, MA, USA) supplemented with $5 \%$ fetal bovine serum (FBS, Gibco, Thermo Fisher), $10 \mathrm{mM} \mathrm{L-glutamine} \mathrm{(GlutaMAX,} \mathrm{Gibco),}$ penicillin $(100 \mathrm{U} / \mathrm{mL})$ (Grünenthal, Germany) and gentamicin $(50 \mathrm{mg} / \mathrm{mL})$ (Krka, Slovenia). Cells were routinely subcultured twice a week and incubated in a humidified atmosphere at $37^{\circ} \mathrm{C}$ and $5 \% \mathrm{CO}_{2}$.

The HPV-positive 2A3 cell line, a kind gift from Prof. Dadachova was established by transfection of $\mathrm{FaDu}$ cells with HPV16 oncogenes E6 and E7 [12]. 2A3 cells were grown in Advanced DMEM supplemented with 5\% fetal bovine serum, $10 \mathrm{mM} \mathrm{L}$-glutamine, penicillin (100 U/ $\mathrm{mL})$, gentamicin $(50 \mathrm{mg} / \mathrm{mL})$ and $1 \mathrm{mg} / \mathrm{mL} \mathrm{G418} \mathrm{disul-}$ fate salt solution (Sigma-Aldrich, MO, USA).

Authentication of $\mathrm{FaDu}, \mathrm{FaDu}-\mathrm{RR}$, and $2 \mathrm{~A} 3$ cells by short tandem repeats profiling was performed using CellCheck 16 - human (IDEXX BioAnalytics, Germany) for authentication of $\mathrm{FaDu}$, and $\mathrm{FaDu}-\mathrm{RR}$ cells (Additional file 1: Final report of laboratory examination) and CellCheck $9-$ human (IDEXX BioAnalytics) for 2A3 cells (Additional file 2: Final report of laboratory examination). The genetic profile of the cell lines used for the study was identical to the publically available genetic profile of these cell lines.

\section{Establishment of isogenic radioresistant cells}

Radioresistant cells were derived from parental $\mathrm{FaDu}$ cells after repeated exposure to ionizing radiation using Gulmay MP1-CP225 X-ray unit (Gulmay Medical Ltd., UK) with a filter consisting of $\mathrm{Cu}$ thickness of $0.55 \mathrm{~mm}$ and $\mathrm{Al}$ thickness of $1.8 \mathrm{~mm}$ at the dose-rate $1.728 \mathrm{~Gy} /$ $\mathrm{min}$. Cells were exposed to $2 \mathrm{~Gy} /$ day for 5 days/week for 3 weeks. After the first irradiation series, 6 different subclones were obtained, and their radiosensitivity was evaluated by clonogenic assay. The subclone FaDu-R1 with the highest surviving fraction at $2 \mathrm{~Gy}$ was selected for further irradiation. After additional irradiation, we were not able to select specific subclones, but whole cell population named FaDu-R2. Subline FaDu-R2 was further irradiated with two more series until radioresistant FaDu-RR cells were established (Fig. 1a). The recovered FaDu-R1, FaDu-R2, and FaDu-RR cells received a total dose of $30 \mathrm{~Gy}, 60 \mathrm{~Gy}$, and $120 \mathrm{~Gy}$, respectively. Since there is no consensus on how to consistently and accurately interpret an increase in cell survival of the irradiated cells as a sign of acquired radioresistant phenotype 


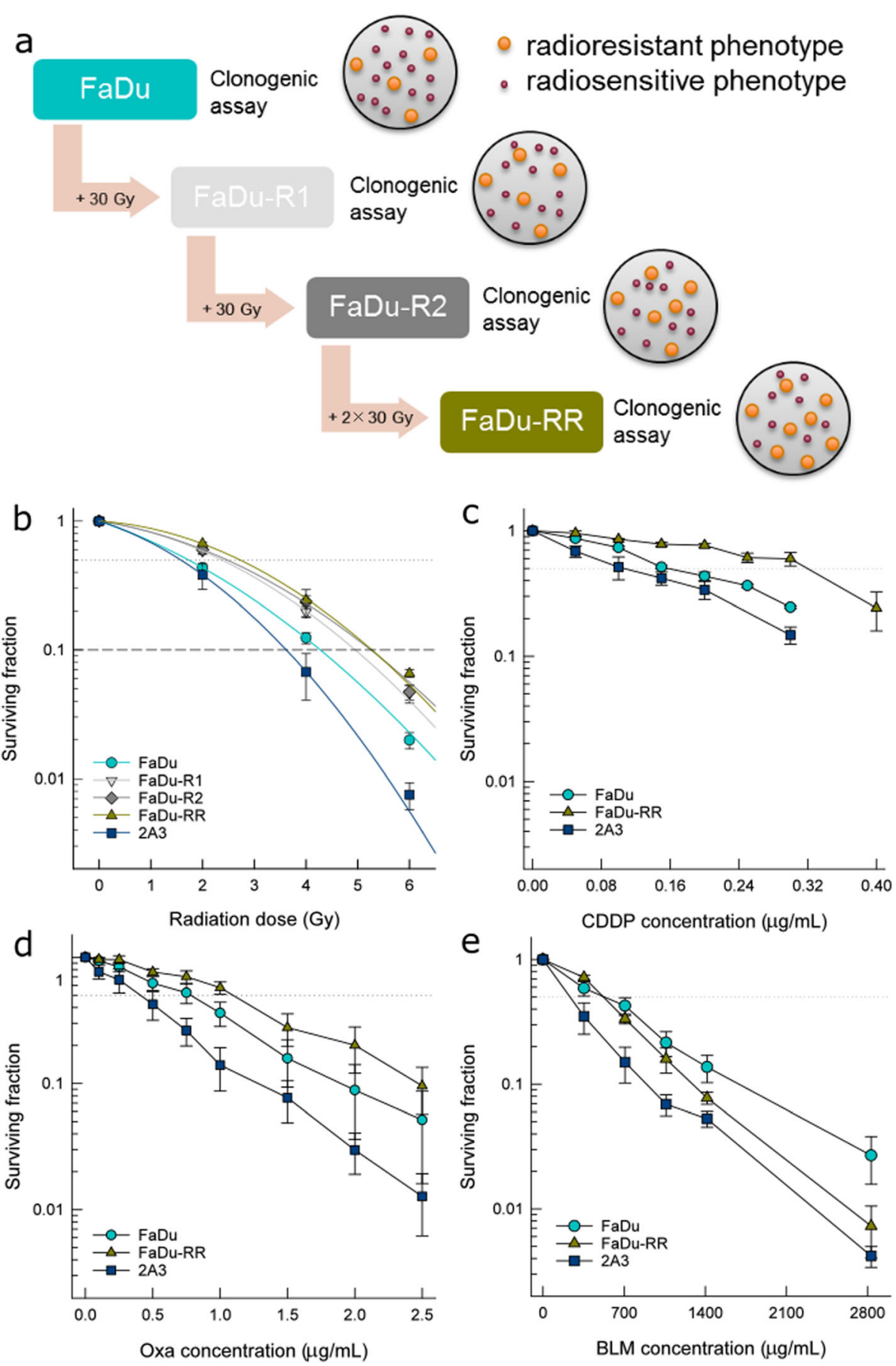

Fig. 1 Radiosensitivity and chemosensitivity of isogenic head and neck squamous cell carcinoma cells with different radiosensitivity. a Schematic representation of the establishment of isogenic radioresistant FaDu-RR cells from parental FaDu cells by repeated exposure to one series (FaDuR1), two series (FaDu-R2), and four series (FaDu-RR) of ionizing radiation; b Surviving fraction of isogenic parental FaDu, radioresistant FaDu-R1, FaDu-R2, and FaDu-RR, and radiosensitive $2 A 3$ cells fitted to LQ model. Symbols are mean values (AM) \pm standard error of the mean (SEM) from three independent experiments. The dashed line indicates the surviving fraction of $0.1\left(D_{10}\right.$ value). c Clonogenic survival of isogenic cells after exposure to (c) cisplatin (CDDP), d oxaliplatin (Oxa) and (e) bleomycin (BLM). The dotted line indicates a surviving fraction of 0.5. Symbols are AM $\pm \mathrm{SEM}, n=3$ 
[9], we compared multiple parameters to describe the survival advantage of the recovered cells. Radiosensitivity was evaluated by comparison of the surviving fraction at 2 Gy (SF2), effective dose killing $50 \%$ of the cells $\left(\mathrm{ED}_{50}\right)$, and the dose required to kill $90 \%$ of the cells $\left(D_{10}\right)$ values as well as $\alpha$ and $\beta$ parameters. For comparison of $\mathrm{ED}_{50}$ and $\mathrm{D}_{10}$ values in radioresistant and parental cells, dose-modifying factor (DMF) was calculated as a ratio of dose in radioresistant cells and in the parental cells. Survival curves were fitted to a linear-quadratic (LQ) model $S f=e^{\left(-\alpha \times D-\beta \times D^{2}\right)}$ using Sigma Plot 13.0 (Systat Software Inc., CA, USA) to estimate $\alpha$ and $\beta$ parameters. The established $\mathrm{FaDu}-\mathrm{RR}$ cells were routinely evaluated for radioresistance and remained radioresistant for more than 4 years of normal maintenance (subculture, freezing and thawing). During this time, maintenance radiation ( 2 Gy/day for 5 days/week for 3 weeks) was applied to restore the radioresistant response in the established $\mathrm{FaDu}-\mathrm{RR}$ cells when radioresistance decreased significantly. Before any experiments were performed, there was a recovery period of minimum 3 weeks to allow $\mathrm{FaDu}-\mathrm{RR}$ to recover and continue normal proliferation.

\section{Radiosensitivity assay}

Radiosensitivity of FaDu, 2A3 and FaDu-RR cells was evaluated by clonogenic assay. Cells were plated at appropriate concentrations, ranging from 400 cells for non-irradiated control up to 8000 cells for 10 Gy irradiation, in a $60-\mathrm{mm}$ tissue culture dish and were irradiated at different doses ranging from 0 Gy to 10 Gy using Gulmay MP1-CP225 X-ray unit as described above. After 10 days, we fixed and stained with crystal violet/methanol solution and counted them. Surviving fraction for each cell line after exposure to ionizing radiation was calculated as a ratio of plating efficiency of treated cells and control cells. The experiment was repeated at least three times in triplicates. The $\mathrm{ED}_{50}$ was determined for each cell line and used to calculate the DMF.

\section{Chemosensitivity assay}

The sensitivity of $\mathrm{FaDu}, 2 \mathrm{~A} 3$ and $\mathrm{FaDu}$-RR cells to cisplatin (CDDP), oxaliplatin (Oxa) and bleomycin (BLM) was evaluated by clonogenic assay. Crystalline CDDP powder (Platinol, Bristol Myers Squibb, Austria) was dissolved in sterile $\mathrm{H}_{2} \mathrm{O}$. For each experiment, a fresh solution of final CDDP concentrations $(0.05 \mu \mathrm{g} / \mathrm{mL}-30 \mu \mathrm{g} / \mathrm{mL}$ ), Oxa (Oxaliplatin Teva, Teva Pharma B. V., the Netherlands) concentrations $(0.1 \mu \mathrm{g} / \mathrm{mL}-2.5 \mu \mathrm{g} / \mathrm{mL}$ ) and BLM (Bleomycin medac, Medac, Germany) concentrations $(354 \mu \mathrm{g} / \mathrm{mL}-2831 \mu \mathrm{g} /$ $\mathrm{mL})$ were prepared in DMEM. Cells were plated in the cell culture media with the drug for continuous drug exposure in a $60-\mathrm{mm}$ tissue culture dish. After 10 days, the colonies were fixed, stained with crystal violet and counted. Plating efficiency and survival fraction were calculated as described in Radiosensitivity assay. The half-maximal inhibitory concentration (the concentration of a chemotherapeutic agent required for a $50 \%$ growth inhibition; $\mathrm{IC}_{50}$ ) was determined for each cell line and drug used. Each experiment was repeated 3 times in triplicates.

\section{Cell proliferation}

Cells were plated on 96 well plates (500 per well) in Advanced DMEM with supplements as described above and allowed to attach for $3 \mathrm{~h}$. Cell viability of $\mathrm{FaDu}$, FaDu-RR, and 2A3 cells was determined by Presto Blue Cell Viability Reagent (Invitrogen, Thermo Fisher Scientific) according to the manufacturer's recommendations every $24 \mathrm{~h}$ for 5 days. After 90 -min incubation in a humidified atmosphere at $37{ }^{\circ} \mathrm{C}$ and $5 \% \mathrm{CO}_{2}$, fluorescence was measured at excitation wavelength $535 \mathrm{~nm}$ and emission wavelength $595 \mathrm{~nm}$ with a microplate reader (Infinite 200, Tecan, Switzerland). Data were fitted to the exponential growth two-parameter equation $y=a \times$ $e^{b \times x}$ in SigmaPlot 13, where $y$ is the measured fluorescence at time point $t, a$ is the fluorescence at time point 0 , $\mathrm{b}$ is a growth rate constant, and $\mathrm{x}$ is a time in hours. Doubling time (DT) for each cell line was then calculated from growth rate constant $\mathrm{b}$ as $=\frac{\ln 2}{b}$.

\section{Cell cycle analysis}

Flow cytometry was used to determine cell cycle distribution of isogenic $\mathrm{FaDu}, \mathrm{FaDu}-\mathrm{RR}$ and 2A3 cells after $5 \mathrm{~Gy}$ irradiation using Gulmay MP1-CP225 X-ray unit as described above. The samples were prepared following the standard procedure using fluorochrome DAPI (4',6-diamidino-2-phenylindole-dihydrochloride), which stoichiometrically binds to the DNA [13, 14]. The samples were acquired using a flow cytometer Partec PAS II (Partec $\mathrm{GmbH}$, Germany). During sample acquisition, at least 30, 000 cells per sample were collected. DNA histograms of the number of cells against observed fluorescence intensity (Additional file 3: Figure S1) were obtained and analysed with MultiCycle AV DNA analysis software (Phoenics Flow Systems, Inc., CA, USA). Distributions of cells in $G_{1}, S$ and $G_{2} / M$ phases of the cell cycle were calculated. The experiment was repeated 3 times.

\section{Detection of apoptosis}

Fold-induction of apoptosis was evaluated using the FITC Annexin V Apoptosis Detection Kit with 7-AAD (Biolegend, CA, USA) according to the manufacturer's instructions, after no irradiation for control cells and after 5 Gy irradiation for irradiated cells using Gulmay MP1-CP225 X-ray unit as described above. After irradiation, cells were incubated for $5 \mathrm{~h}, 24 \mathrm{~h}, 48 \mathrm{~h}$, and $72 \mathrm{~h}$. Trypsinized cell suspension was combined with the 
collected cell media to include dead cells and centrifuged to remove the trypsin and cell media. Early apoptotic (Annexin V-positive and 7AAD-negative), late apoptotic and/or necrotic (Annexin V-positive and 7AAD-positive), necrotic (Annexin $\mathrm{V}$-negative and 7AAD-positive) and viable (Annexin V-negative and 7AAD-negative) cells were analyzed by FACSCanto II flow cytometer (BD Biosciences, CA, USA) within $10 \mathrm{~min}$ (Additional file 4: Figure S2). Fold-induction of apoptosis was determined as the sum of early and late apoptotic (Annexin V-positive) cells at a specific time point, normalized to the sum of early and late apoptotic cells in control non-irradiated cells at 5 $h$. Fold-change of cell viability was determined as percentage of viable non-irradiated or 5 Gy irradiated cells at specific time point, normalized to the percentage of control non-irradiated viable cells at $5 \mathrm{~h}$. The experiment was repeated 4 times.

\section{YH2AX immunofluorescence}

$\mathrm{FaDu}, \mathrm{FaDu}-\mathrm{RR}$, and 2A3 cells were seeded on glass coverslips (Knittelglass, Germany), incubated overnight and irradiated with 5 Gy using Gulmay MP1-CP225 X-ray unit as described above. Control non-irradiated cells (0 h) and irradiated cells at different time points after irradiation $(15 \mathrm{~min}, 30 \mathrm{~min}, 45 \mathrm{~min}, 1 \mathrm{~h}, 2 \mathrm{~h}, 5 \mathrm{~h}, 24 \mathrm{~h}, 48 \mathrm{~h}$ and $72 \mathrm{~h}$ ), were fixed and stained for $\gamma \mathrm{H} 2 \mathrm{AX}$ immunofluorescence as described previously [15]. $\gamma \mathrm{H} 2 \mathrm{AX}$ foci were viewed under the Olympus BX51 fluorescence microscope at 100-fold magnification. Images were analysed using Image J $1.51 \mathrm{~g}$ software tool (NIH, MD, USA) to score $\gamma \mathrm{H} 2 \mathrm{AX}$ foci/nuclei. First, DAPI-stained nuclei were selected to omit nuclear debris, apoptoticlike nuclei, and enlarged nuclei. Then, nuclei outlines were overlaid on $\gamma \mathrm{H} 2 \mathrm{AX}$ foci image to count the number of foci in each nucleus. Foci were counted semiautomatically by empirically setting a threshold level for $\gamma \mathrm{H} 2 \mathrm{AX}$ foci. For each condition, at least 250 nuclei were analysed and data from three independent experiments were pooled together. A cut-off value for $\gamma \mathrm{H} 2 \mathrm{AX}$ positive cells was 90th percentile of background $\gamma \mathrm{H} 2 \mathrm{AX}$ foci in control non-irradiated cells. To evaluate the kinetics of $\gamma \mathrm{H} 2 \mathrm{AX}$ foci resolution, the experimental data were fitted to two-phase exponential decay equation $y$ $=$ Plateau + SpanFast $\times e^{K_{\text {fast }} \times x}+$ SpanSlow $\times e^{K_{\text {slow }} \times x}$ to evaluate the half-life of $\gamma \mathrm{H} 2 \mathrm{AX}$ foci in the fast and slow phases of DSB repair [16].

\section{Gene expression analysis}

To study the expression of genes involved in DNA damage signalling, Human DNA Damage Signalling Pathway $\mathrm{RT}^{2}$ ProfilerTM PCR Array (PAHS-029Z, Qiagen, Germany) was used. A list of 84 pathway specific and 5 house-keeping genes on this array is available in Additional file 5: Table
S1. Genomic DNA control, reverse transcription control, and positive PCR controls were also included on the array. Cells were irradiated using a Gulmay MP1-CP225 X-ray unit as described above. Total RNA was isolated from nonirradiated and 5 Gy-irradiated $\mathrm{FaDu}, 2 \mathrm{~A} 3$ and $\mathrm{FaDu}-\mathrm{RR}$ cells $5 \mathrm{~h}$ after irradiation, by using RNeasy Plus Mini Kit (Qiagen). Briefly, RNA concentration and sample purity $\left(\mathrm{A}_{260 / 280}\right)$ were determined spectrophotometrically and $2 \mu \mathrm{g}$ total RNA was used to synthesize cDNA using $\mathrm{RT}^{2}$ First Strand Kit (Qiagen). Real time reverse transcription polymerase chain reaction (RT-PCR) was carried out on QuantStudio 3 Real-time PCR System (Applied Biosystems, USA) using $\mathrm{RT}^{2}$ qPCR Sybr Green ROX Mastermix (Qiagen). RT-PCR cycling conditions were $10 \mathrm{~min}$ at $95^{\circ} \mathrm{C}$ for activation of HotStart DNA Taq Polymerase, followed by 40 amplification cycles of $15 \mathrm{~s}$ at $95^{\circ} \mathrm{C}$ and $2 \mathrm{~min}$ at $60^{\circ} \mathrm{C}$. RTPCR specificity was verified by melting curve analysis, immediately after each RT-PCR run. Melt curve program consisted of $1 \mathrm{~min}$ at $95^{\circ} \mathrm{C}, 2 \mathrm{~min}$ at $65^{\circ} \mathrm{C}$ and dissociation step from $65^{\circ} \mathrm{C}$ to $95^{\circ} \mathrm{C}$ at $2{ }^{\circ} \mathrm{C} /$ minute.

Data were analyzed on the GeneGlobe Data Analysis Center (Qiagen). Data were normalized to automatically selected housekeeping genes with the most stable expression. For comparison of non-irradiated control cells, data were normalized to the gene expression of housekeeping genes $A C T B, B 2 M$ and RPLPO, and for comparison of 5 Gy-irradiated cells, data were normalized to the gene expression of housekeeping genes $A C T B$ and $R P L P O$. Fold change in gene expression was calculated using the $\Delta \Delta C T$ method [8]. We used 1.5 fold-change in gene expression as a threshold and $p$-values less than 0.05 to identify significantly different gene expression. For statistical analysis, Student's t-test (two-tail distribution and equal variances between the two samples) was used on the replicate $2^{-\Delta \Delta C T}$ values for each gene in each treatment group compared to the control group from 3 independent experiments.

Additionally, we used GeneMANIA and Reactome Pathway Database for to help predict the functions of the identified differentially expressed genes in isogenic cells with different radiosensitivity and in response to 5 Gy irradiation in these isogenic cells. GeneMANIA was used to identify functions of differentially expressed genes and visualize interactions between the differentially expressed genes [17]. These interactions included physical interaction (two gene products are linked if they were found to interact in a protein-protein interaction study), predicted interactions (two proteins are predicted to interact if their orthologs are known to interact in another organism), co-expression (two genes are linked if their expression levels are similar across conditions in a gene expression study), genetic interaction (two genes are functionally associated if the effects of perturbing one gene were found to be modified by perturbations to 
a second gene), pathway interactions (two gene products are linked if they participate in the same reaction within a pathway), co-localization (two genes are linked if they are both expressed in the same tissue or if their gene products are both identified in the same cellular location), and shared protein domains (two gene products are linked if they have the same protein domain). In addition, Reactome Pathway Database was used for the visualization and comparison of the signalling pathways affected by the differential gene expression in isogenic cells with different radiosensitivity and by exposure to 5 Gy irradiation [18].

\section{Statistics}

SigmaPlot 13.0 (Systat Software Inc., San Jose, CA, USA) was used for statistical analysis. Data were tested for normality of distribution using the Shapiro-Wilk test. For normally distributed data, arithmetic mean (AM) and standard error of the mean (SEM) were calculated. Unless otherwise stated, all multiple comparisons were tested using the Holm-Sidak method after One Way ANOVA. Differences were considered significant for $P$ values less than 0.05 .

\section{Results}

\section{Radiosensitivity of isogenic cells}

After repeated exposure to radiation, different isogenic radioresistant cells (Fig. 1a), derived from human pharyngeal SCC FaDu, were established. Their radiosensitivity (Fig. 1b) was evaluated by calculating SF2, ED 5 , $D_{10}, \alpha$, and $\beta$ parameters and $\alpha / \beta$ ratio of the LQ model (Additional file 6: Table S2). FaDu-RR cells had a significantly increased $\mathrm{SF} 2, \mathrm{ED}_{50}$, and $\mathrm{D}_{10}$ values, and significantly decreased $\alpha$ and $\alpha / \beta$ parameters in comparison to parental FaDu cells and isogenic 2A3 cells. The latter had significantly decreased $\mathrm{ED}_{50}$ and increased $\alpha$ and $\alpha /$ $\beta$ parameters compared to parental $\mathrm{FaDu}$ and isogenic $\mathrm{FaDu}-\mathrm{RR}$ cells. Based on these results, FaDu-RR cells displayed a radioresistant, and $2 \mathrm{~A} 3$ cells a radiosensitive phenotype in comparison to parental FaDu cells. Plating efficiency of control non-irradiated $\mathrm{FaDu}, \mathrm{FaDu}-\mathrm{RR}$, and $2 \mathrm{~A} 3$ cells was $46.1,46.9$, and $45.6 \%$ respectively, and did not differ significantly between the cell lines.

\section{Chemosensitivity}

In addition to radioresistance, FaDu-RR cells displayed cross-resistance to CDDP (Fig. 1c) and Oxa (Fig. 1d), but not to BLM (Fig. 1e). Namely, IC $_{50}$ values for CDDP and Oxa in radioresistant FaDu-RR cells were potentiated 1.8-fold and 1.5-fold, respectively, while no difference in BLM sensitivity was observed, when compared to the parental cell line (Table 1). In comparison to the latter, increased sensitivity to CDDP, Oxa and BLM was also indicated in the radiosensitive $2 \mathrm{~A} 3$ cells.

\section{Cell proliferation}

Similar, statistically non-significant growth rates and DTs of isogenic FaDu, FaDu-RR and 2A3 cells (Fig. 2a) were observed. DT of parental FaDu cells was $24.5 \pm 2.3$ $\mathrm{h}$, of radioresistant $\mathrm{FaDu}-\mathrm{RR}$ cells $33.8 \pm 1.5 \mathrm{~h}$, and of radiosensitive $2 \mathrm{~A} 3$ cells $29.6 \pm 2.4 \mathrm{~h}$.

\section{Cell cycle distribution}

Before irradiation, the cell cycle distribution of isogenic $\mathrm{FaDu}, \mathrm{FaDu}-\mathrm{RR}$, and $2 \mathrm{~A} 3$ cells did not differ significantly between cells (Fig. 2b). Primarily, cells were in $G_{1}$ phase (51\%), followed by those in the $S$ phase $(37 \%)$ and $G_{2} / M$ phase $(12 \%)$. We did not observe difference in chromosome number in these isogenic cell lines (Additional file 3: Figure $S 1$ ). Five hours post-irradiation, cell cycle distribution among isogenic cells was preserved (Fig. 2c), although different from the distribution of non-irradiated cells. The majority of cells were in $\mathrm{S}$ phase, while the percentage of cells in $G_{1}$ phase decreased and increased in $G_{2} / M$ phase (Additional file 7: Figure S3). However, $24 \mathrm{~h}$ after $5 \mathrm{~Gy}$ irradiation, the percentage of $G_{1}$ cells was similar or higher as before irradiation. Specifically for $\mathrm{FaDu}$ and $\mathrm{FaDu}-\mathrm{RR}$ cells the difference in $G_{1}$ cells was significantly higher after $24 \mathrm{~h}$, while in $2 \mathrm{~A} 3$ cells, there were more $\mathrm{G}_{1}$ cells after $24 \mathrm{~h}$, however the increase was not significant. Meanwhile, the minority of cells were in S phase. Among isogenic cell lines, statistically significant differences in cell cycle distribution were observed. In comparison to the parental $\mathrm{FaDu}$ and radioresistant FaDu-RR cells, the percentage of cells in $\mathrm{S}$ phase was the lowest in radiosensitive $2 \mathrm{~A} 3$ cells $(5 \%)$, while in the $\mathrm{G}_{2} / \mathrm{M}$-phase it was the highest (33\%) (Fig. 2d).

\section{Radiation-induced apoptosis}

We observed very low levels of early and late apoptotic cells (Additional file 8: Table S3). To identify differences in response to irradiation, fold-induction of apoptosis was determined for each specific time point relative to control non-irradiated cells at $5 \mathrm{~h}$. In non-irradiated control cells, no induction of apoptosis was detected, while in isogenic $\mathrm{FaDu}, \mathrm{FaDu}-\mathrm{RR}$ and $2 \mathrm{~A} 3$ cells (Fig. 3), apoptosis was induced by irradiation. In general, significantly higher foldinduction of apoptosis was observed $72 \mathrm{~h}$ after irradiation in parental $\mathrm{FaDu}$ and radiosensitive $2 \mathrm{~A} 3$ cells, compared to the earlier time points $(5,24$ and $48 \mathrm{~h}$ ), while foldinduction of apoptosis in radioresistant FaDu-RR was sustained in time (Additional file 9: Figure S4).

These results parallel the cell viability of isogenic cell lines after exposure to $5 \mathrm{~Gy}$ irradiation. While $\mathrm{FaDu}$ and $2 \mathrm{~A} 3$ fold-change of cell viability was significantly reduced $72 \mathrm{~h}$ after $5 \mathrm{~Gy}$ irradiation compared to non-irradiated cells at all timepoints, FaDu-RR fold-change of cell viability was less affected, and was significantly lower only in comparison to non-irradiated FaDu-RR cells $72 \mathrm{~h}$ after plating (Additional file 10: Figure S5). 
Table 1 Half-maximal inhibitory concentration $\left(\mathrm{IC}_{50}\right)$ values of isogenic cells to chemotherapeutics

\begin{tabular}{llllll}
\hline Cytotoxic drug $(\mu \mathrm{g} / \mathrm{mL})$ & $\mathrm{FaDu}$ & FaDu-RR & Fold-potentiation $^{\mathrm{a}}$ & $2 \mathrm{2A3}$ & Fold-potentiation $^{\mathrm{a}}$ \\
\hline Cisplatin & $0.16 \pm 0.007$ & $0.284 \pm 0.02^{\mathrm{b}}$ & 1.8 & $0.1 \pm 0.03$ & 0.7 \\
Oxaliplatin & $0.75 \pm 0.15$ & $1.12 \pm 0.15^{\mathrm{c}}$ & 1.5 & $0.41 \pm 0.13$ & 0.5 \\
Bleomycin & $551 \pm 132$ & $521 \pm 18$ & 0.9 & $249 \pm 63$ & 0.5
\end{tabular}

${ }^{\mathrm{a}}$ Fold-potentiation compared to parental FaDu cell line. ${ }^{\mathrm{b}}$ significant difference compared to FaDu and $2 \mathrm{~A} 3$ cells. ${ }^{\mathrm{c}}$ significant difference compared to $2 \mathrm{~A} 3$. Values are $\mathrm{AM} \pm \mathrm{SEM}$

\section{$\mathrm{\gamma H} 2 \mathrm{AX}$ immunofluorescence}

A different temporal expression of $\gamma \mathrm{H} 2 \mathrm{AX}$ foci in isogenic cells (Fig. 4a) was observed. Induction of foci was detected as early as $15 \mathrm{~min}$ after irradiation in the parental $\mathrm{FaDu}$ and radiosensitive $2 \mathrm{~A} 3$ cells, whereas, in radioresistant FaDu-RR cells, significant induction was observed 30 min after irradiation. Accumulation of $\gamma \mathrm{H} 2 \mathrm{AX}$ foci was most prominent in radiosensitive $2 \mathrm{~A} 3$ cells, in which the peak was observed already $15 \mathrm{~min}$ after irradiation. After 30 to $45 \mathrm{~min}$, the peak of $\gamma \mathrm{H} 2 \mathrm{AX}$ foci was observed also in radioresistant FaDu-RR cells, while in FaDu cells, the $\gamma \mathrm{H} 2 \mathrm{AX}$ foci accumulated more slowly and reached a peak expression $2 \mathrm{~h}$ after irradiation. The median number of foci observed at the peak also differed between the cells, ranging from 25 in radiosensitive $2 \mathrm{~A} 3$ cells, 14 in parental FaDu cells to 7 foci in radioresistant FaDu-RR cells. The number of residual $\gamma \mathrm{H} 2 \mathrm{AX}$ foci $72 \mathrm{~h}$ after irradiation remained significantly higher compared to control nonirradiated isogenic cells.

Furthermore, differences were also in the percent of $\gamma \mathrm{H} 2 \mathrm{AX}$-positive cells (Fig. 4b) and in the $\gamma \mathrm{H} 2 \mathrm{AX}$ foci resolution (Fig. 4c). A maximum of $\gamma \mathrm{H} 2 \mathrm{AX}$-positive cells

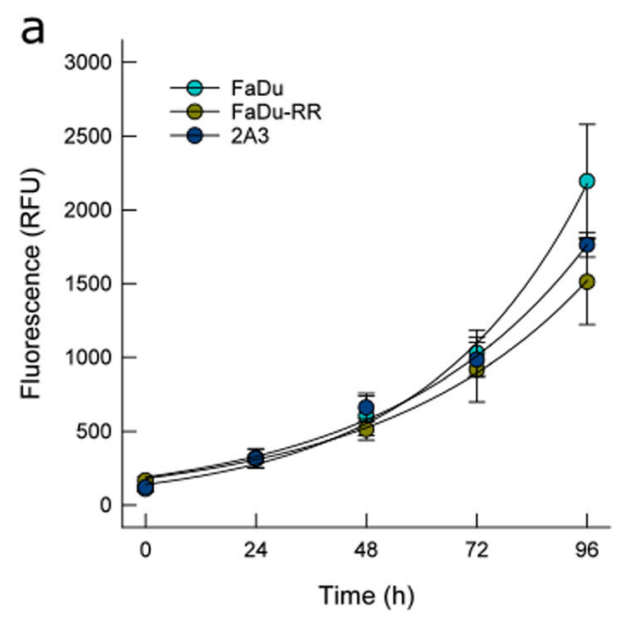

b

C
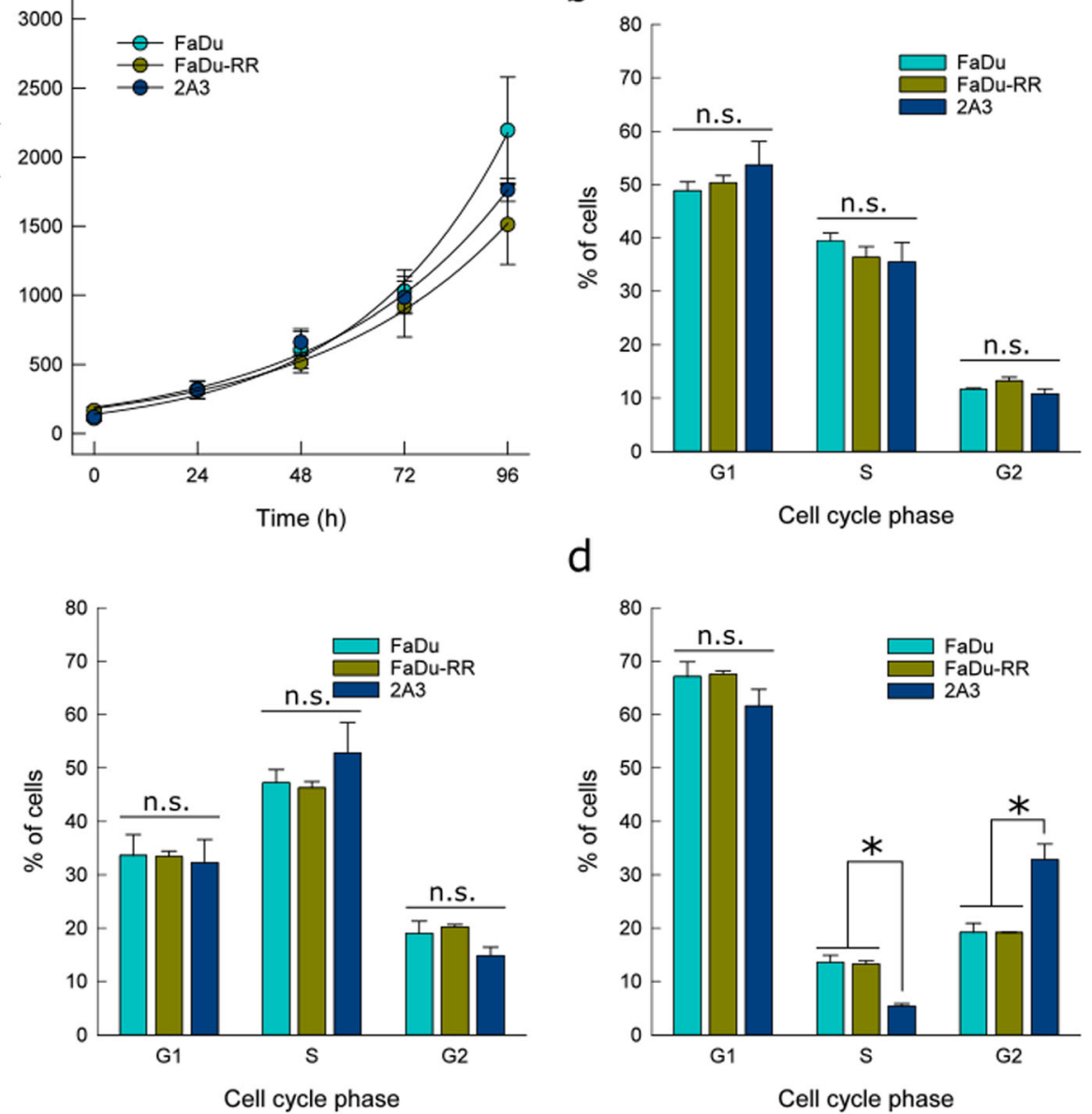

C

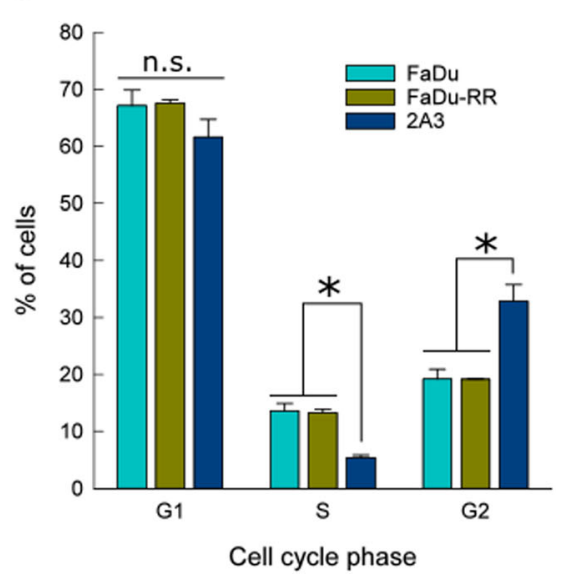

Fig. 2 Cell proliferation and cell cycle distribution of isogenic head and neck squamous cell carcinoma cells. a No difference in cell proliferation of isogenic cells with different radiosensitivity was observed. b Cell cycle phase distribution before irradiation, c $5 \mathrm{~h}$ after 5 Gy irradiation, and $\mathbf{d}$ $24 \mathrm{~h}$ after $5 \mathrm{~Gy}$ irradiation. Symbols and bars AM \pm SEM from three independent experiments. * indicates significant difference; $\mathrm{n} . \mathrm{s}$. - non-significant 


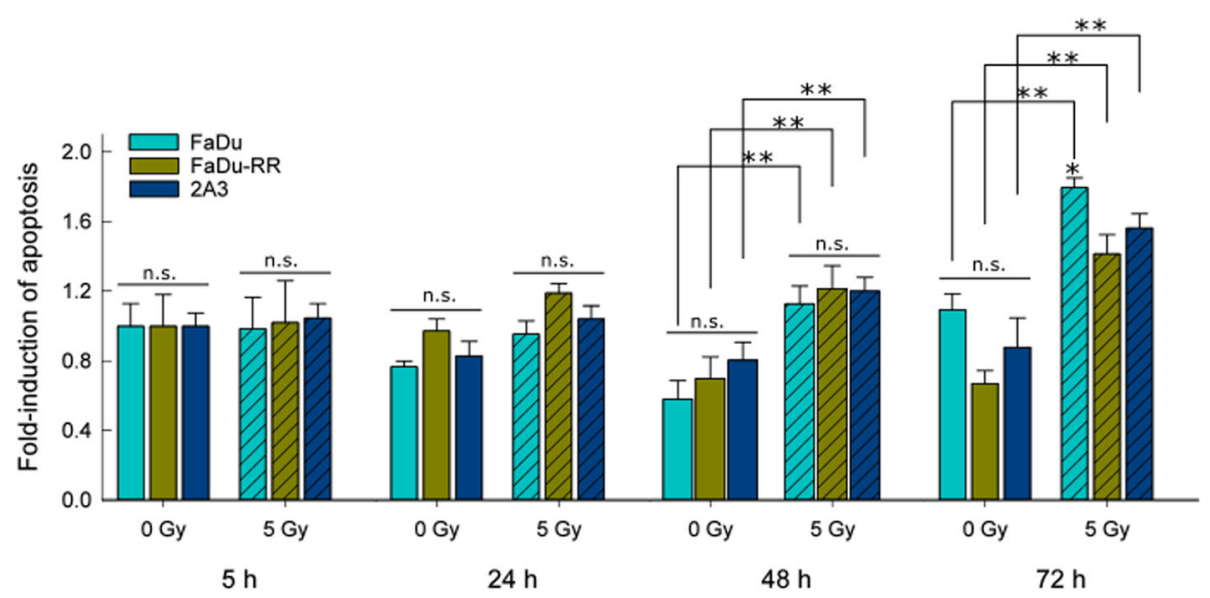

Fig. 3 Fold-induction of apoptosis after 5 Gy irradiation in isogenic FaDu, FaDu-RR, and 2A3 cells. Significantly higher fold-induction of apoptosis was observed in FaDu $72 \mathrm{~h}$ after irradiation, in comparison to FaDu-RR or $2 \mathrm{~A} 3$ cells. Bars are AM \pm SEM from three independent experiments. ${ }^{* *}$ indicates a significant difference between 5 Gy irradiated and control non-irradiated cells; ${ }^{*}$ indicates a significant difference compared to FaDuRR and $2 \mathrm{~A} 3$ cells; n.s. - non-significant

was observed at the peak of $\gamma \mathrm{H} 2 \mathrm{AX}$ formation. Namely, $86 \pm 5 \%$ of parental FaDu cells, $72 \pm 8 \%$ of radioresistant $\mathrm{FaDu}-\mathrm{RR}$ cells, and $93 \pm 2 \%$ of radiosensitive $2 \mathrm{~A} 3$ cells were $\gamma \mathrm{H} 2 \mathrm{AX}$-positive at the peak of $\gamma \mathrm{H} 2 \mathrm{AX}$ foci. In parental $\mathrm{FaDu}$ and radiosensitive $2 \mathrm{~A} 3$ cells, a fraction of $\gamma \mathrm{H} 2 \mathrm{AX}$-positive cells remained significantly elevated up to $48 \mathrm{~h}$ after irradiation, while in radioresistant $\mathrm{FaDu}$-RR cells a fraction of $\gamma \mathrm{H} 2 \mathrm{AX}$-positive cells was significantly increased only between 30 and $45 \mathrm{~min}$ after irradiation. In the fast phase of DNA DSB repair, radioresistant $\mathrm{FaDu}-\mathrm{RR}$ and radiosensitive $2 \mathrm{~A} 3$ cells had a short halflife of $\gamma \mathrm{H} 2 \mathrm{AX}$ foci (34 and $11 \mathrm{~min}$, respectively), while the half-life of $\gamma \mathrm{H} 2 \mathrm{AX}$ foci in parental FaDu cells was $2.5 \mathrm{~h}$. In the slow phase of DNA DSB repair, radioresistant $\mathrm{FaDu}-\mathrm{RR}$ cells also had the shortest half-time of $\gamma \mathrm{H} 2 \mathrm{AX}$ foci $(4.5 \mathrm{~h})$, while parental $\mathrm{FaDu}$ and radiosensitive $2 \mathrm{~A} 3$ had much longer half-time of $\gamma \mathrm{H} 2 \mathrm{AX}$ foci (31.8 and $24.1 \mathrm{~h}$, respectively).

Additionally, significantly enlarged cell nuclei, with more than 2-fold increase in the nuclear area, 48 and 72 $\mathrm{h}$ after irradiation (Additional file 11: Figure S6) were observed. The fraction of cells with significantly enlarged nuclei was the highest in radiosensitive $2 \mathrm{~A} 3$ cells $(40 \%$ at $48 \mathrm{~h}$ and $46 \%$ at $72 \mathrm{~h}$ ), intermediate in parental $\mathrm{FaDu}$ cells $(29.2 \%$ at $48 \mathrm{~h}$ and $31.5 \%$ at $72 \mathrm{~h})$ and the lowest in radioresistant $\mathrm{FaDu}-\mathrm{RR}$ cells $(22.3 \%$ at $48 \mathrm{~h}$ and $12.3 \%$ at $72 \mathrm{~h}$ ). These cells also had a persistently high number of residual $\gamma \mathrm{H} 2 \mathrm{AX}$ foci $(21$ and $15 \gamma \mathrm{H} 2 \mathrm{AX}$ foci in $\mathrm{FaDu}, 13$ and $17 \gamma \mathrm{H} 2 \mathrm{AX}$ foci in FaDu-RR, and 17 and $16 \gamma \mathrm{H} 2 \mathrm{AX}$ foci in $2 \mathrm{~A} 3$ at 48 and $72 \mathrm{~h}$, respectively).

DNA damage signalling and repair (DSR) gene expression The expression of 84 relevant genes involved in DNA DSR was determined in parental $\mathrm{FaDu}$, radioresistant
FaDu-RR, and radiosensitive $2 \mathrm{~A} 3$ cells, before and $5 \mathrm{~h}$ after 5 Gy irradiation.

An altered DNA DSR gene expression between nonirradiated parental $\mathrm{FaDu}$, radioresistant $\mathrm{FaDu}-\mathrm{RR}$, and radiosensitive $2 \mathrm{~A} 3$ cells was observed. Namely, of the 84 DNA DSR genes included in the analysis, 12 genes were under-expressed in radioresistant FaDu-RR cells (Fig. 5a). In radiosensitive $2 \mathrm{~A} 3$ cells, 22 genes were overexpressed and 6 genes were under-expressed for a total of 28 differentially expressed genes (Fig. 5b). Of these differentially expressed genes, two genes, BLM and $R N F 168$, were both under-expressed in FaDu-RR and 2A3 cells, while no genes were over-expressed in both $\mathrm{FaDu}-\mathrm{RR}$ and $2 \mathrm{~A} 3$ cells. We identified four genes (FANCD2, GADD45A, H2AFX, and XRCC2) which were under-expressed in radioresistant FaDu-RR cells, yet over-expressed in radiosensitive 2A3 cells. Summary of the DNA DSR gene expression in non-irradiated FaDuRR and 2A3 cells is provided in Table 2.

Functional analysis associated the 12 underexpressed genes in radioresistant $\mathrm{FaDu}-\mathrm{RR}$ with response to ionizing radiation, response to radiation, cellular response to ionizing radiation, DNA recombination, regulation of DNA metabolic process, positive regulation of DNA metabolic process, and DNA $\mathrm{N}$-glycosylase activity (Additional file 12: Figure S7a). Interactions between these differentially expressed genes in radioresistant $\mathrm{FaDu}-\mathrm{RR}$ cells included physical and predicted interactions, co-expression, pathways, co-localization and shared protein domains (Additional file 12: Figure S7b).

Differentially expressed genes in radiosensitive 2A3 cells were associated with response to radiation, DNA recombination, DSB repair, damaged DNA binding, 


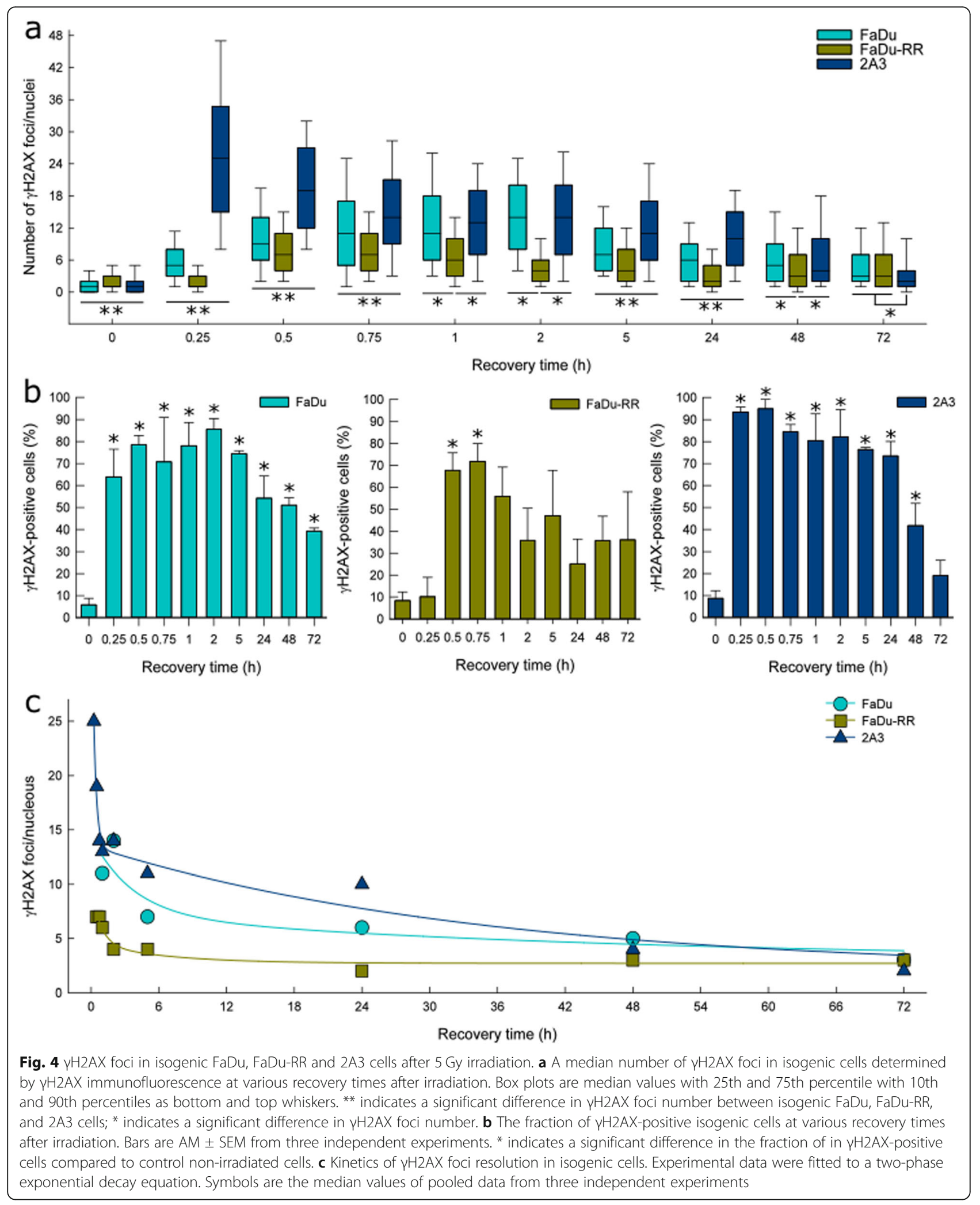



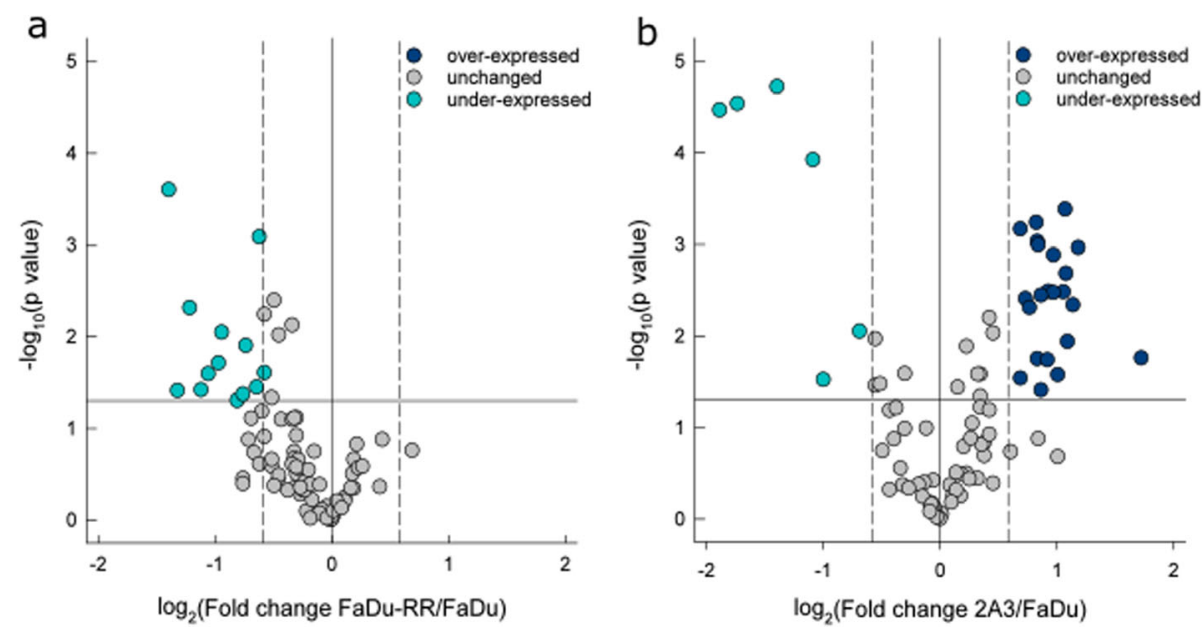

Fig. 5 DNA damage signalling and repair gene expression in non-irradiated isogenic FaDu, FaDu-RR, and 2A3 cells. a Gene expression in nonirradiated radioresistant FaDu-RR relative to non-irradiated parental FaDu cells; $\mathbf{b}$ gene expression in non-irradiated radiosensitive $2 \mathrm{~A} 3$ cells relative to parental FaDu cells. Volcano plots show the fold change in gene expression and statistical significance ( $p$-value). The horizontal line shows the statistical significance threshold ( $p$-value $<0.05$ ). Two vertical dashed lines show the threshold of over-expressed (right) and under-expressed genes (left), while the solid vertical line shows no change in gene expression. Symbols represent the mean gene expression of each tested gene in FaDu-RR and 2A3 cells relative to parental FaDu cells from three independent experiments

response to ionizing radiation, DNA damage checkpoint and DNA integrity checkpoint (Additional file 12: Figure S7c). These differentially expressed genes in radiosensitive $2 \mathrm{~A} 3$ cells are connected through physical and predicted interactions, co-expression, genetic interactions, pathways, co-localization and shared protein domains (Additional file 12: Figure S7d).

We visualized the signalling pathways in which the differentially expressed genes were involved with Reactome Pathway Database. Differentially expressed genes in radioresistant $\mathrm{FaDu}-\mathrm{RR}$ and radiosensitive $2 \mathrm{~A} 3$ cells were involved in DNA DSB repair, base excision repair, nucleotide excision repair (NER), mismatch repair, and Fanconi anemia pathway, as well as cell cycle checkpoints, meiosis, chromosome maintenance and mitotic $\mathrm{G}_{1}-\mathrm{G}_{1} / \mathrm{S}$ phases (Additional file 12: Figure S7e). Specifically in radiosensitive 2A3 cells, one under-expressed genes was involved in the intrinsic pathway of apoptosis.

Differences were observed also in radiation-induced gene expression of DNA DSR genes $5 \mathrm{~h}$ after irradiation in isogenic $\mathrm{FaDu}, \mathrm{FaDu}-\mathrm{RR}$ and $2 \mathrm{~A} 3$ relative to nonirradiated control cells. Specifically, 5 genes were overexpressed in parental FaDu cells (Fig. 6a), whereas in radioresistant FaDu-RR cells, 12 genes were overexpressed, and 2 genes were under-expressed for a total of 14 differentially expressed genes (Fig. 6b). In radiosensitive 2A3 cells, 1 gene was under-expressed (Fig. 6c). Of these differentially expressed genes, 4 genes (BLM, GADD45A, MDC1, PMS1) were over-expressed in both parental $\mathrm{FaDu}$ and radioresistant $\mathrm{FaDu}$-RR cells. Specifically, in radioresistant FaDu-RR cells, 8 genes (ATR, XPA, MSH3, $M C P H 1, H 2 A F X, N B N, E R C C 2, X R C C 2)$ were over- expressed and 2 genes $(B B C 3, C R Y 1)$ were under-expressed. One gene, $X R C C 3$, was under-expressed specifically in radiosensitive $2 \mathrm{~A} 3$ cells after $5 \mathrm{~Gy}$ irradiation. A summary of the radiation-induced DNA DSR gene expression in $\mathrm{FaDu}$, $\mathrm{FaDu}-\mathrm{RR}$, and $2 \mathrm{~A} 3$ cells is provided in Table 3.

Functional analysis of the differentially expressed genes in 5 Gy-irradiated parental $\mathrm{FaDu}$ cells associated these genes with DSB repair, DNA recombination, cellular response to ionizing radiation, recombinational repair, single-stranded DNA binding, DSB repair via homologous recombination and regulation of cyclin-dependent protein serine/threonine kinase activity (Additional file 13: Figure S8a). We identified physical and predicted interactions, co-expression, and colocalization of differentially expressed genes in irradiated parental FaDu cells (Additional file 13: Figure S8b). In irradiated radioresistant FaDu-RR cells, differentially expressed genes were associated with DNA recombination, DNA integrity checkpoint, DNA damage checkpoint, response to radiation, recombinational repair, DNA-dependent ATPase activity and DSB repair via homologous recombination (Additional file 13: Figure S8c) and were associated through physical and predicted interactions, co-expression and colocalization, genetic interaction, pathways and shared protein domains (Additional file 13: Figure S8d). Overrepresented pathways in irradiated parental $\mathrm{FaDu}$ and radioresistant $\mathrm{FaDu}$-RR cells were identified with Reactome Pathway Database, indicating differences in DNA repair, cell cycle and programmed cell death (Additional file 13: Figure S8e). The differences in DNA repair included DNA DSB repair, mismatch repair, and NER. Regarding DNA DSB repair, radioresistant FaDu-RR cells had more overexpressed genes involved in non-homologous end joining, 
Table 2 Basal gene expression of genes involved in DNA damage signaling pathway in non-irradiated isogenic radioresistant FaDuRR and radiosensitive $2 \mathrm{~A} 3$ cells compared to non-irradiated parental FaDu cells

\begin{tabular}{|c|c|c|c|c|c|}
\hline Gene $^{a}$ & FaDu-RR ${ }^{b}$ & P value & $2 A 3^{d}$ & P value ${ }^{c}$ & DNA damage signaling pathways \\
\hline APEX1 & & & 2.11 & 0.002 & BER \\
\hline ATM & & & 2.08 & 0.003 & ATM/ATR signaling, DSB repair, apoptosis, cell cycle \\
\hline BARD1 & & & 1.66 & 0.004 & ATM/ATR signaling, other DNA repair genes, apoptosis \\
\hline$B B C 3$ & & & -1.99 & 0.03 & apoptosis \\
\hline$B L M$ & -2.60 & 0.0003 & -3.35 & 0.00003 & DSB repair \\
\hline CHEK1 & & & 1.96 & 0.001 & ATM/ATR signaling, DSB repair, cell cycle \\
\hline$C \mid B 1$ & & & -3.69 & 0.00003 & other DNA repair genes, apoptosis \\
\hline DDB2 & & & 1.78 & 0.02 & NER \\
\hline$E R C C 2$ & -2.35 & 0.005 & & & NER \\
\hline FANCD2 & -1.74 & 0.05 & 1.78 & 0.0010 & ATM/ATR signaling, other DNA repair genes \\
\hline FEN1 & & & 1.79 & 0.001 & BER \\
\hline GADD45A & -2.19 & 0.04 & 3.30 & 0.02 & other DNA repair genes \\
\hline H2AFX & -1.92 & 0.009 & 1.61 & 0.03 & ATM/ATR signaling, DSB repair \\
\hline HUS1 & -2.10 & 0.03 & & & ATM/ATR signaling, DSB repair \\
\hline MBD4 & -1.54 & 0.0008 & & & BER \\
\hline MLH1 & & & 2.13 & 0.01 & DSB repair, mismatch repair \\
\hline MSH3 & & & 1.77 & 0.0006 & mismatch repair \\
\hline OGG1 & & & 1.70 & 0.005 & NER, BER \\
\hline PCNA & -1.57 & 0.04 & & & NER, BER, mismatch repair \\
\hline PMS1 & & & 1.90 & 0.003 & mismatch repair \\
\hline PNKP & & & -1.60 & 0.009 & NER \\
\hline PPM1D & & & 1.82 & 0.04 & cell cycle \\
\hline PRKDC & & & 1.89 & 0.02 & DSB repair, apoptosis \\
\hline RAD1 & & & 2.10 & 0.0004 & ATM/ATR signaling, other DNA repair genes \\
\hline RAD17 & & & 1.96 & 0.003 & ATM/ATR signaling, other DNA repair genes \\
\hline RAD18 & & & 1.82 & 0.004 & other DNA repair genes \\
\hline RBBP8 & & & 2.27 & 0.001 & ATM/ATR signaling, other DNA repair genes \\
\hline REV1 & & & 1.61 & 0.0007 & other DNA repair genes \\
\hline RNF168 & -1.69 & 0.04 & -2.13 & 0.0001 & ATM/ATR signaling, other DNA repair genes \\
\hline SUMO1 & & & -2.60 & 0.00002 & other DNA repair genes \\
\hline TOPBP1 & -1.68 & 0.01 & & & ATM/ATR signaling, other DNA repair genes \\
\hline UNG & & & 2.20 & 0.005 & BER \\
\hline$X R C C 2$ & -2.47 & 0.04 & 2.01 & 0.03 & DSB repair \\
\hline$X R C C 3$ & -1.96 & 0.02 & & & other DNA repair genes \\
\hline
\end{tabular}

${ }^{\mathrm{a}}$ Gene symbol according to HUGO Gene Nomenclature Committee; ${ }^{\mathrm{b}}$ Fold regulation in gene expression in radioresistant FaDu cells in comparison to parental FaDu cells. Positive fold regulation values indicate gene over-expression, negative fold regulation values indicate gene under-expression; ${ }^{\mathrm{C}}$ The $\mathrm{P}$ values are calculated based on a Student's t-test of the replicate $2^{(-\Delta \Delta \mathrm{CT})}$ values for each gene in the parental FaDu cells and radioresistant FaDu-RR or radiosensitive $2 \mathrm{~A} 3$ cells, and differences in gene expression were considered significant for $P$ values less than $0.05 ;{ }^{d}$ Fold regulation in gene expression in radiosensitive $2 A 3$ cells in comparison to parental FaDu cells. BER base excision repair, DSB double-strand break, NER nucleotide excision repair

homology-directed repair, and DNA DSB response than parental FaDu cells. Similarly, radioresistant FaDu-RR cells had more over-expressed genes involved in the cell cycle than parental $\mathrm{FaDu}$ cells. Specifically, in radioresistant FaDu-RR cells, $B B C 3$ gene, involved in the intrinsic pathway of apoptosis, was under-expressed. On the other hand, radiosensitive 2A3 cells had under-expressed XRCC3 gene involved in homology-directed repair, whereas no change in expression of genes involved in cell cycle and programmed cell death was observed.

By direct comparison of gene expression in 5 Gy-irradiated radioresistant $\mathrm{FaDu}-\mathrm{RR}$ cells and parental $\mathrm{FaDu}$ 

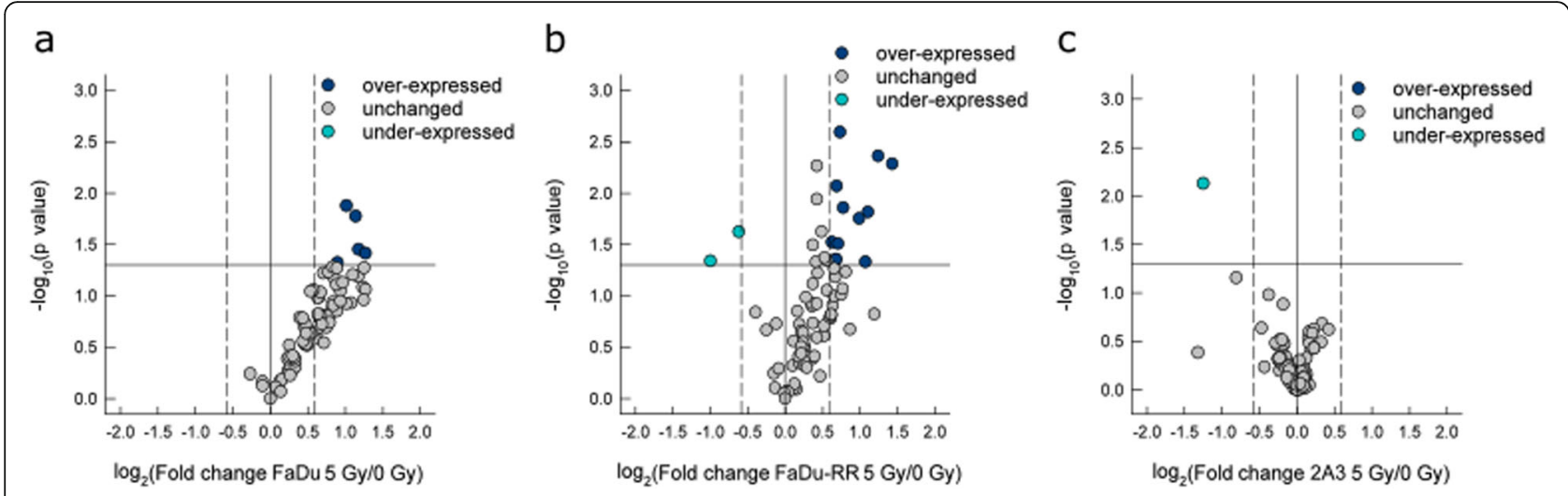

Fig. 6 DNA damage signalling and repair gene expression in irradiated isogenic FaDu, FaDu-RR, and 2A3 cells. a Gene expression in 5 Gyirradiated parental FaDu cells relative to non-irradiated FaDu cells; $\mathbf{b}$ gene expression in 5 Gy-irradiated radioresistant FaDu-RR relative to nonirradiated FaDu-RR cells; c gene expression in 5 Gy-irradiated radioresistant 2A3 cells relative to non-irradiated 2A3 cells. Volcano plots show the fold change in gene expression and statistical significance ( $p$-value). The horizontal line shows the statistical significance threshold ( $p$-value $<$ 0.05). Two vertical dashed lines show the threshold of over-expressed (right) and under-expressed genes (left). The solid vertical line shows no change in gene expression. Symbols represent the mean gene expression of each tested gene in 5 Gy-irradiated cells relative to pertinent nonirradiated cells from three independent experiments

cells, 2 differentially expressed genes in FaDu-RR cells were detected, of which $B L M$ gene was under-expressed and XPA gene was over-expressed (Fig. 7a). On the other hand, 5 Gy irradiated radiosensitive $2 \mathrm{~A} 3$ cells had 25 differentially expressed genes in comparison to 5 Gy irradiated parental FaDu cells, of which 4 genes were over-expressed and 21 genes were under-expressed (Fig. 7b). Of these differentially expressed genes, the $B L M$ gene was under-expressed in both radioresistant FaDu-RR and radiosensitive $2 \mathrm{~A} 3$ cells, while the $X P A$ gene was

Table 3 Radiation-induced gene expression of genes involved in DNA damage signaling pathway in isogenic parental FaDu, radioresistant FaDu-RR and radiosensitive $2 \mathrm{~A} 3$ cells $5 \mathrm{~h}$ after $5 \mathrm{~Gy}$ irradiation compared to non-irradiated parental FaDu, radioresistant FaDu-RR and radiosensitive $2 \mathrm{~A} 3$ cells, respectivelly

\begin{tabular}{|c|c|c|c|c|c|c|c|}
\hline Gene $^{a}$ & $\mathrm{FaDu}^{\mathrm{b}}$ & P value ${ }^{c}$ & FaDu-RR ${ }^{b}$ & P value ${ }^{c}$ & $2 \mathrm{~A} 3^{\mathrm{b}}$ & P value & DNA damage signaling pathways \\
\hline ATR & & & 1.71 & 0.01 & & & ATM/ATR signaling, DSB repair, apoptosis, cell cycle \\
\hline$B B C 3$ & & & -2.00 & 0.05 & & & apoptosis \\
\hline$B L M$ & 2.26 & 0.04 & 2.69 & 0.005 & & & DSB repair \\
\hline CRY1 & & & -1.54 & 0.02 & & & other DNA repair genes \\
\hline ERCC2 & & & 1.54 & 0.03 & & & NER \\
\hline GADD45A & 2.02 & 0.01 & 2.36 & 0.004 & & & other DNA repair genes \\
\hline H2AFX & & & 1.63 & 0.03 & & & ATM/ATR signaling, DSB repair \\
\hline MCPH1 & & & 1.66 & 0.003 & & & cell cycle \\
\hline MDC1 & 1.86 & 0.05 & 1.59 & 0.04 & & & DSB repair, cell cycle \\
\hline $\mathrm{MSH} 3$ & & & 1.60 & 0.04 & & & mismatch repair \\
\hline NBN & & & 1.61 & 0.009 & & & DSB repair \\
\hline PMS1 & 2.20 & 0.02 & 2.15 & 0.02 & & & mismatch repair \\
\hline PRKDC & 2.41 & 0.04 & & & & & DSB repair, apoptosis \\
\hline$X P A$ & & & 1.99 & 0.02 & & & NER \\
\hline$X R C C 2$ & & & 2.10 & 0.05 & & & DSB repair \\
\hline$X R C C 3$ & & & & & -2.40 & 0.007 & other DNA repair genes \\
\hline
\end{tabular}

${ }^{a}$ Gene symbol according to HUGO Gene Nomenclature Committee; ${ }^{\text {b }}$ Fold regulation in gene expression in 5 Gy-irradiated cells in comparison to non-irradiated cells. Positive fold regulation values indicate gene over-expression, negative fold regulation values indicate gene under-expression; ${ }^{c}$ The $P$ values were calculated based on a Student's t-test of the replicate $2^{(-\Delta \Delta C T)}$ values for each gene in the $5 \mathrm{~Gy}$-irradiated and non-irradiated cells, and differences in gene expression were considered significant for $\mathrm{P}$ values less than 0.05 . DSB double-strand break, NER nucleotide excision repair 

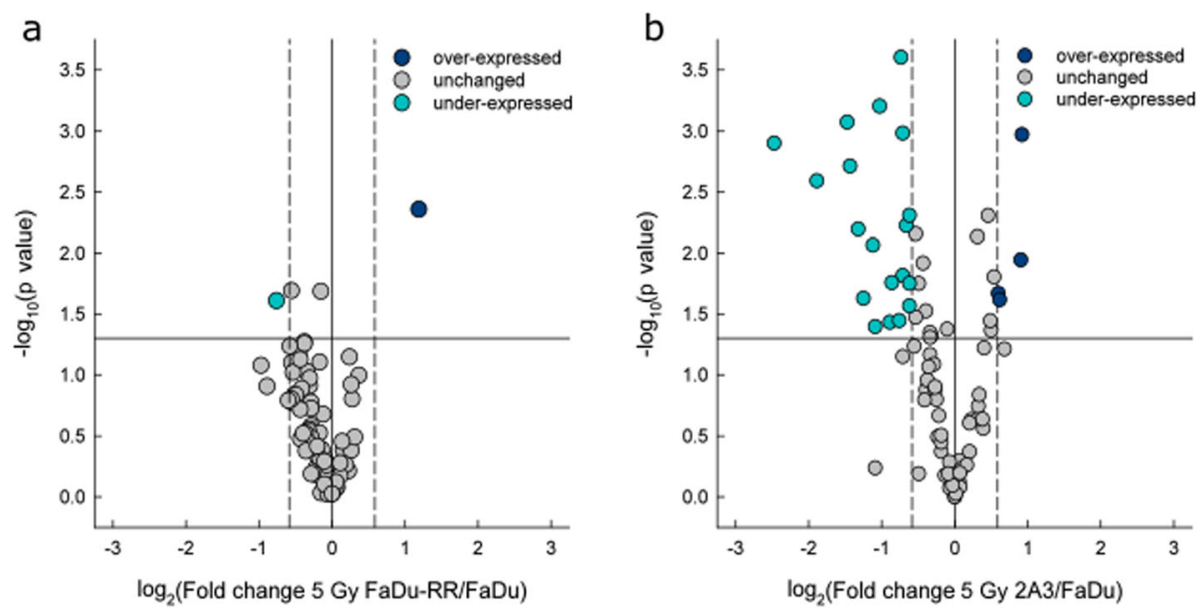

Fig. 7 DNA damage signalling and repair gene expression in irradiated isogenic FaDu, FaDu-RR, and 2A3 cells. a Gene expression in 5 Gyirradiated FaDu-RR cells relative to 5 Gy-irradiated FaDu cells. b Gene expression in 5 Gy-irradiated $2 \mathrm{~A} 3$ cells relative to 5 Gy-irradiated FaDu cells. Volcano plots show the fold change in gene expression and statistical significance ( $p$-value). The horizontal line shows the statistical significance threshold (p-value $<0.05$ ). Two vertical dashed lines show the threshold of over-expressed (right) and under-expressed genes (left). The solid vertical line shows no change in gene expression. Symbols represent the mean gene expression of each tested gene in 5 Gy-irradiated radioresistant FaDu-RR and radiosensitive $2 \mathrm{~A} 3$ cells relative to $5 \mathrm{~Gy}$-irradiated parental FaDu cells from three independent experiments

over-expressed in radioresistant FaDu-RR, but underexpressed in radiosensitive 2A3 cells. Summary of the DNA DSR gene expression in 5 Gy-irradiated FaDu-RR and $2 \mathrm{~A} 3$ cells relative to 5 Gy-irradiated FaDu cells is provided in Table 4.

According to the Qiagen's classification of DNA damage signalling genes, differentially expressed genes in radioresistant FaDu-RR cells were involved in DSB repair and NER. On the other hand, differentially expressed genes in 5 Gy-irradiated $2 \mathrm{~A} 3$ cells were involved in DSB repair, ATM/ATR signalling, NER, base excision repair, other repair, apoptosis and cell cycle. Functional analysis associated the differentially expressed genes $B L M$ and XPA in 5 Gy-irradiated FaDu-RR cells with DNA secondary structure binding, single-stranded DNA binding, DNA catabolic process, and structurespecific DNA binding (Additional file 14: Figure S9a). No known interaction networks between $B L M$ and XPA genes were identified (Additional file 14: Figure S9b). Differentially expressed genes in 5 Gy-irradiated 2A3 cells were associated with DSB repair, DNA catabolic process, DNA damage checkpoint, cell cycle checkpoint, DNA integrity checkpoint, damaged DNA binding, and DNA recombination (Additional file 14: Figure S9c). Using GeneMANIA physical and predicted interactions, pathway, co-expression and co-localization networks among these differentially expressed genes were identified (Additional file 14: Figure S9d).

\section{Discussion}

In order to modulate cellular radioresistance and sensitivity, mechanisms responsible for these phenomena need to be identified. Isogenic cell lines with different radiosensitivity can serve as a good predictive model, as survival changes can be directly attributed to specific modifications in the intrinsic cellular features. Pairs of isogenic cell lines with different radiosensitivity have been established from different solid tumour cell lines, such as head and neck SCC [11, 19-24], prostate carcinoma $[25,26]$, non-small cell lung cancer $[27,28]$. We successfully established radioresistant $\mathrm{FaDu}-\mathrm{RR}$ cells from parental FaDu cells by repeated exposure to irradiation, while radiosensitive $2 \mathrm{~A} 3$ cells were derived from parental $\mathrm{FaDu}$ cells by stable transfection with HPV16 oncogenes E6 and E7 [12]. Although variations in radiosensitivity of HPV-positive cells exist, they are generally more radiosensitive than the HPV-negative cells $[3,4]$. Radiosensitivity of $2 \mathrm{~A} 3$ cells was confirmed in vivo in experimentally induced tumours in immunodeficient mice [5]. To the best of our knowledge, this is the only study comparing both radioresistant and radiosensitive isogenic cells to parental cells, with a specific focus on gene expression in response to irradiation.

Radioresistant FaDu-RR cells were established by repeated exposure to daily $2 \mathrm{~Gy}$ doses from parental $\mathrm{FaDu}$ cells, making them 1.6-fold more radioresistant than the parental cells. The observed potentiation of radioresistance in $\mathrm{FaDu}-\mathrm{RR}$ cells is comparable to the potentiation of radioresistance observed in other isogenic models of radioresistance $[23,28,29]$. The induced radioresistance was either long-term, more than 3 years of passaging [20,21], or short-term, from 4 weeks to 18 weeks [22, 25, 28-30], however, it could be restored after additional irradiation [30, 31]. FaDu-RR displayed long-term radioresistance of more than 4 years. Protocols used in these 
Table 4 DNA damage signaling gene expression in 5 Gy-irradited radioresistant FaDu-RR cells and 5 Gy-irradiated radiosenstive 2A3 cells compared to 5 Gy-irradiated parental FaDu cells

\begin{tabular}{|c|c|c|c|c|c|}
\hline Gene $^{a}$ & FaDu-RR ${ }^{b}$ & P value ${ }^{c}$ & $2 \mathrm{~A} 3^{\mathrm{d}}$ & P value ${ }^{c}$ & DNA damage signaling pathways \\
\hline APEX1 & & & 1.89 & 0.001 & BER \\
\hline ATM & & & 1.87 & 0.01 & ATM/ATR signaling, DSB repair, apoptosis, cell cycle \\
\hline$B A X$ & & & -2.49 & 0.006 & apoptosis \\
\hline$B B C 3$ & & & -3.65 & 0.003 & apoptosis \\
\hline$B L M$ & -1.69 & 0.02 & -7.86 & 0.000 & DSB repair \\
\hline BRIP1 & & & -2.35 & 0.02 & Other repair genes \\
\hline CDC25A & & & -1.59 & 0.006 & ATM/ATR signaling, cell cycle \\
\hline CHEK2 & & & -1.65 & 0.02 & ATM/ATR signaling, other repair genes, apoptosis, cell cycle \\
\hline$C \mid B 1$ & & & -5.60 & 0.001 & Other repair genes, apoptosis \\
\hline FANCA & & & -2.02 & 0.001 & Other repair genes \\
\hline HUS1 & & & -1.65 & 0.001 & ATM/ATR signaling, DSB repair \\
\hline MDC1 & & & -1.66 & 0.000 & DSB repair, cell cycle \\
\hline MLH1 & & & 1.51 & 0.02 & DSB repair, mismatch repair \\
\hline$M P G$ & & & -1.85 & 0.04 & BER \\
\hline NBN & & & -1.83 & 0.02 & DSB repair \\
\hline NTHL1 & & & -1.54 & 0.02 & BER \\
\hline PNKP & & & -2.77 & 0.000 & NER \\
\hline RBBP8 & & & 1.53 & 0.02 & ATM/ATR signaling, other DNA repair genes \\
\hline RNF168 & & & -2.77 & 0.001 & ATM/ATR signalling, other DNA repair genes \\
\hline RPA1 & & & -1.70 & 0.04 & NER, DSB repair \\
\hline SMCIA & & & -1.53 & 0.005 & ATM/ATR signalling, other DNA repair genes \\
\hline SUMO1 & & & -2.73 & 0.002 & Other DNA repair genes \\
\hline TP73 & & & -2.12 & 0.04 & Mismatch repair, apoptosis, cell cycle \\
\hline$X P A$ & 2.28 & 0.004 & -1.54 & 0.03 & NER \\
\hline$X R C C 3$ & & & -2.20 & 0.01 & other DNA repair genes \\
\hline
\end{tabular}

${ }^{\mathrm{a}}$ Gene symbol according to HUGO Gene Nomenclature Committee; ${ }^{\text {b }}$ Fold regulation in gene expression in 5 Gy-irradiated FaDu-RR cells in comparison to 5 Gyirradiated FaDu cells. Positive fold regulation values indicate gene over-expression, negative fold regulation values indicate gene under-expression; ${ }^{\circ}$ The $P$ values were calculated based on a Student's t-test of the replicate $2^{(-\Delta \Delta C T)}$ values for each gene in the 5 Gy-irradiated and non-irradiated cells, and differences in gene expression were considered significant for $\mathrm{P}$ values less than 0.05 . ${ }^{\mathrm{d}}$ Fold regulation in gene expression in 5 Gy-irradiated $2 \mathrm{~A} 3$ cells in comparison to $5 \mathrm{~Gy}$ irradiated FaDu cells. DSB double-strand break, BER base excision repair, NER nucleotide excision repair

studies varied significantly in specific parameters, such as dose/fraction (from $0.5 \mathrm{~Gy}$ to $10 \mathrm{~Gy}$ ), total dose received (from $10 \mathrm{~Gy}$ up to more than $1600 \mathrm{~Gy}$ ), overall treatment time (from 5 days up to 6 years), recovery periods ( $12 \mathrm{~h}$, daily, weekly, fortnightly intervals) [20, 26, 32, 33]. On the other hand, the recovery period was not always defined in time units, but in the percentage of culture confluence, ranging from 50 to $80 \%$ prior to the next fraction [24, 34]. These parameters were determined experimentally, based on the radiosensitivity of the parental cells, and allowing selection of radioresistant clones with replicative potential. In our preliminary study, $10 \mathrm{~Gy} /$ fraction with $48 \mathrm{~h}$ recovery between fractions was too high for the recovery of radioresistant cells with replicative potential. This was supported by the observation that dose per fraction ranging from 2 to $6 \mathrm{~Gy}$, was sufficient for a selection of radioresistant clones, while lower or higher doses were not [33]. However, others have used lower or higher doses/fraction from 0.5 to $10 \mathrm{~Gy}$ combined with shorter recovery period for low dose/fraction, and longer for high dose/fraction to successfully establish radioresistant cells $[20,32]$. The observed survival advantages were also inconsistently reported in terms of increased surviving fraction at a specific dose of radiation [11, 19, 22, 23, 25, 29, 32], the dose modifying factor at $2 \mathrm{~Gy}$ irradiation dose [28], clonogenic potential [27], mean inactivation dose ratio $[28,35]$, the dose required to reduce cell survival to $10 \%$ [33], and $\alpha / \beta$ ratio of LQ model [23]. Variations in parameters reporting the survival advantage of radioresistant cells also limit direct comparison of the extent of induced radioresistance. Significant increase in radioresistance can be achieved with either $10 \mathrm{~Gy}$ or $1600 \mathrm{~Gy}$ of the total dose [26, 32], however, the potentiation of radioresistance cannot be directly compared due to variations in parameters measuring the survival advantages in these cells. In addition to variabilities in protocols used for 
selection of radioresistant cells, a successful selection of radioresistant cells is dependent also on the cell type [9].

Prolonged exposure to irradiation can select the more radioresistant cells within the cell population, such as cells expressing markers of cancer stem cells (CSC), commonly associated with increased radioresistance [19]. On the other hand, radiation induced genetic instability can further select the more radioresistant cells [9]. During the establishment of radioresistant cells in our study, we have first selected different subclones. By further irradiation, we were not able to select different subclones, but rather whole cell populations. The increased radioresistance observed in the established $\mathrm{FaDu}-\mathrm{RR}$ cells is a combination of clonal selection of radioresistant cells within the existing cell population and radiation-induced genetic variability as confirmed by differential gene expression.

Changes in the cell cycle distribution can confer different radiosensitivity of cells due to variations in radiosensitivity of cell cycle phases - cells in S-phase being the most radioresistant. We did not observe any difference in cell cycle distribution and cell proliferation rate in non-irradiated isogenic cells. Similarly, no change in the cell cycle distribution or growth rate was observed in other isogenic models of radioresistance [11, 22, 23, 27, 33, 36, 37]. However, $5 \mathrm{~h}$ after 5 Gy irradiation, we observed a decrease in $\mathrm{G}_{1}$-phase cells and an increase in S-phase and $\mathrm{G}_{2} / \mathrm{M}$-phase cells with no significant difference between the studied isogenic cells. Similarly, no change in cell cycle distribution was observed in radioresistant and parental cells $4 \mathrm{~h}$ after 2 Gy irradiation [25]. While the percent of $\mathrm{G}_{2} / \mathrm{M}$-phase parental and radioresistant cells remained unchanged $24 \mathrm{~h}$ after irradiation, the percent of radiosensitive cells in $G_{2} / M$ phase significantly increased. Other reports show a similar level of $\mathrm{G}_{2} /$ $\mathrm{M}$ arrest in response to irradiation in other radiosensitive cells $[3,4,24]$. Increase in $G_{2} / M$-phase cells was observed both in radiosensitive and radioresistant cells, but the disturbance of the cell cycle in response to irradiation was longer in radiosensitive cells [38]. Based on these results, other mechanisms than alterations in cell cycle regulation were involved in the radioresistant phenotype of FaDu-RR cells.

Alterations in radiation-induced apoptosis can also contribute to altered cellular radiosensitivity. In our study, no apoptosis was observed in non-irradiated isogenic cells and none of the differentially expressed genes observed in the non-irradiated radioresistant cells were associated with the apoptotic processes. On the other hand, the proapoptotic $B B C 3$ gene was under-expressed in $2 \mathrm{~A} 3$ radiosensitive cells. The reason for this could be a transfection of radiosensitive cells by HPV protein E6 [12], which is known to interact with pro-apoptotic proteins to prevent apoptosis in HPV-positive cells $[39,40]$. In response to 5 Gy irradiation, fold-induction of apoptosis was the highest in parental cells, and only non- significantly increased in the radioresistant cells $72 \mathrm{~h}$ after irradiation. In addition, proapoptotic $B B C 3$ was under-expressed in radioresistant cells in response to irradiation. This indicates the involvement of antiapoptotic regulatory mechanisms in radioresistant cells. Variability in the induction of apoptosis in response to radiation exists likely due to different radiation dose, time after irradiation, and the method used to detect specific hallmarks of apoptosis. Similarly, in the study by Wei QC et al., no induction of apoptosis or apoptotic morphological features were observed up to $48 \mathrm{~h}$ after 6 Gy irradiation in radioresistant and parental cells [28]. Contrary, $24 \mathrm{~h}$ after $10 \mathrm{~Gy}$ irradiation less apoptotic cells were detected in the radioresistant population [27].

Cell survival after irradiation largely depends on the balance between DNA damage signalling, induction, and repair. We evaluated DNA damage by immunofluorescence staining of $\gamma \mathrm{H} 2 \mathrm{AX}$ foci, surrogate markers of DNA DSBs [41]. We observed no significant difference in endogenous levels of $\gamma \mathrm{H} 2 \mathrm{AX}$ foci in the studied isogenic cells. However, the range of the observed $\gamma \mathrm{H} 2 \mathrm{AX}$ foci levels was the highest in the $2 \mathrm{~A} 3$ radiosensitive cells. More endogenous DNA damage was expected in the cells due to E6mediated oxidative stress [42]. On the other hand, some studies reported radioresistant cells to have less endogenous DNA damage, more effective DNA repair, and enhanced levels of ROS scavengers [19, 23-25, 27, 28].

After irradiation, the induction of $\gamma \mathrm{H} 2 \mathrm{AX}$ foci was the most prominent in radiosensitive cells, while in radioresistant cells the induction of foci was delayed. In addition, at the peak of $\gamma \mathrm{H} 2 \mathrm{AX}$ foci expression, radioresistant cells displayed the lowest number of $\gamma \mathrm{H} 2 \mathrm{AX}$ foci/ nucleus in contrast to the highest number of $\gamma \mathrm{H} 2 \mathrm{AX}$ foci/nucleus observed in radiosensitive cells. The highest percent of $\gamma \mathrm{H} 2 \mathrm{AX}$-positive cells was observed in radiosensitive cells and the lowest in radioresistant cells. As expected, the resolution of $\gamma \mathrm{H} 2 \mathrm{AX}$ foci was the most prominent in radioresistant cells. Similarly to our results, less $\gamma \mathrm{H} 2 \mathrm{AX}$ foci/nucleus were observed in radioresistant cells in comparison to radiosensitive cells after irradiation [43]. Loss of $\gamma \mathrm{H} 2 \mathrm{AX}$ foci was the most prominent in radioresistant cells, indicating a greater DNA DSB repair as another alteration contributing to radioresistant phenotype [44].

DNA DSB is the most lethal lesion induced by irradiation, and if not repaired, leads to cell death. Biphasic kinetics of DNA DSB repair reflects the mechanistic differences of the two major repair pathways, homologous recombination (HR) and non-homologous end-joining (NHEJ) [45]. NHEJ is a fast, highly efficient, error-prone process active throughout the cell cycle, but predominantly in $G_{1}$-phase cells. On the other hand, $H R$ is a slow, accurate process active in $S$ - and $G_{2}$-phase cells in the presence of sister chromatid. In our study, radiosensitive 
cells displayed initial fast repair, followed by a slow resolution of $\gamma \mathrm{H} 2 \mathrm{AX}$ foci, while the radioresistant cells exhibited fast $\gamma \mathrm{H} 2 \mathrm{AX}$ foci resolution in both phases of DSB repair. Similar to our study, faster disappearance of $\gamma \mathrm{H} 2 \mathrm{AX}$ was observed in other radioresistant cells compared to slower $\gamma \mathrm{H} 2 \mathrm{AX}$ foci resolution in radiosensitive cells $[38,46]$. We concluded that the higher ability to repair DSB observed in studied radioresistant cells, in comparison to both parental and radiosensitive cells by both NHEJ and HR, importantly contributes to the cellular radioresistance.

Incorrect rejoining of radiation-induced DNA breaks can lead to structural and numerical chromosomal alterations [47]. As observed by flow cytometry isogenic $\mathrm{FaDu}$, $\mathrm{FaDu}-\mathrm{RR}$, and $2 \mathrm{~A} 3$ cells do not differ in chromosome number. On the other hand, alterations in chromosome structure can affect gene expression. A more detailed genomic analysis is needed to specifically identify radiationinduced mutations, loss and gain of genetic material, and chromosomal abberations. The observed underexpression and over-expression of DNA DSR genes could be either due to alterations of the genetic material, or due to changes in the translation of DNA.

We further focused on DNA DSR gene expression because alterations of these genes can importantly determine radiosensitivity [48]. We observed alterations in the expression of studied genes in non-irradiated radioresistant and radiosensitive cells, compared with parental cells. We also observed over-expression of DNA DSR gene expression in parental and radioresistant cells, but not in radiosensitive cells $5 \mathrm{~h}$ after irradiation. Similarly, other studies found more DNA repair genes to be up-regulated in radioresistant cells $6 \mathrm{~h}$ after irradiation than in radiosensitive cells [49]. Prolonged transcriptional activity of DNA damage response, cell cycle and apoptosis-related genes was observed in radiosensitive cells in comparison to radioresistant cells in response to irradiation [38].

We identified 4 genes of interest, FANCD2, GADD45A, $H 2 A F X$, and $X R C C 2$ to be over-expressed in radiosensitive cells, but under-expressed in radioresistant cells. FANCD2 gene product is an important component of the Fanconi anemia pathway of DNA damage response and acts as a recruitment factor for other DNA repair proteins [50]. FANCD2 accumulation is associated with HPV-activated Fanconi anemia pathway and is essential for the maintenance of viral episomes in HPV-infected cells [51]. Overexpression of FANCD2 in radiosensitive $2 \mathrm{~A} 3$ cells could be associated with the HPV16 E6 and E7 transfection.

GADD45A gene product is involved in cell cycle regulation, DNA repair, and apoptosis [52]. Over-expression of GADD45A promotes transcriptional activity through global demethylation $[53,54]$. Based on these results, the detected over-expression of GADD $45 \mathrm{~A}$ in radiosensitive cells could be associated with the increased transcriptional activity and differential gene expression observed in these cells in comparison to parental cells. On the other hand, silencing GADD45A is associated with increased survival, reduced apoptosis, and reduced sensitivity to CDDP [54, 55]. Under-expression of GADD45A could contribute to CDDP cross-resistance in radioresistant $\mathrm{FaDu}-\mathrm{RR}$ cells. These data suggest a radioprotective mechanism through underexpression of GADD45A. However, contrary to these observations, under-expression of GADD45A in melanoma cells increased sensitivity to CDDP and enhanced CDDP-induced DNA damage [56]. In addition, GADD45A gene and protein expression are increased in response to a variety of DNA damaging agents, including ionizing radiation [52, 55, 57]. Similarly, we observed an increase in GADD45A gene expression $5 \mathrm{~h}$ after irradiation in parental and radioresistant cells, but not in radiosensitive cells. It is possible that intrinsically higher levels of GADD $45 A$ in radiosensitive cells limit any further increase in the expression of this gene in response to irradiation. The observed over-expression of genes in parental and radioresistant cells, but not in radiosensitive cells, could be associated with GADD45A-mediated increase in transcriptional activity [53, 54].

H2AFX gene encodes histone $\mathrm{H} 2 \mathrm{AX}$, which is rapidly phosphorylated to $\gamma \mathrm{H} 2 \mathrm{AX}$ in response to DNA DSBs induced by radiation or DNA damaging agents. $\gamma \mathrm{H} 2 \mathrm{AX}$ then interacts with $\mathrm{MDC1}$, another over-expressed gene in radioresistant cells in response to irradiation, and recruits other DNA damage response-associated proteins to the site of the DSB [16]. Silencing $H 2 A X$ induced activation of epithelialmesenchymal transition factors, and promoted metastatic behavior [58]. Over-expression of H2AFX observed in radiosensitive cells is in agreement with the observed higher range of $\gamma \mathrm{H} 2 \mathrm{AX}$ foci observed by immunofluorescence. On the other hand, over-expression of $H 2 A F X$ in radioresistant cells, but not parental or radiosensitive cells, in response to irradiation could be an indication of enhanced recognition of DSBs, and faster disappearance of $\gamma \mathrm{H} 2 \mathrm{AX}$ foci observed.

$X R C C 2$ gene product is a paralogue of RAD51 protein, involved in DNA DSB repair via HR [59]. Knockdown of $X R C C 2$ in colon carcinoma cells decreased cell proliferation, increased apoptosis and lead to cell cycle arrest induced by irradiation [60]. XRCC2 is also involved in the regulation of replication fork progression to prevent DNA damage and genomic instability [61]. Although $X R C C 2$ is under-expressed in radioresistant cells, its expression is up-regulated early in the response to $5 \mathrm{~Gy}$ irradiation, which could contribute to faster DSB repair by HR in radioresistant cells. No change in XRCC2 expression in parental and radiosensitive cells was observed in response to irradiation which is in agreement with slower HR repair of DNA DSB.

Another Rad51 paralogue, XRCC3 was the only underexpressed gene in radiosensitive cells in response to the irradiation, indicating on a possible mechanism of increased 
sensitivity to ionizing radiation. As shown by Cheng J et al, knockdown of XRCC3 increased radiosensitivity in vitro and in vivo, while high expression of XRCC3 correlated with radio- and chemoresistance [62].

By direct comparison of gene expression in 5 Gy-irradiated isogenic cells, we identified another gene of interest, $X P A$, possibly involved in the radioresistance mechanism. XPA gene product plays a central role in the NER pathway, through which CDDP-DNA adducts are repaired [63]. XPA was over-expressed in radioresistant cells, but under-expressed in radiosensitive cells in response to irradiation. This was also observed in radioresistant glioblastoma cells [64]. The increased expression of XPA, and consequently activated NER could be associated with cross-resistance to CDDP, observed in radioresistant cells. In a parallel study, we demonstrated a more efficient repair of CDDP and BLM-induced DNA damage in radioresistant cells compared to parental cells [15]. Other mechanisms contributing to CDDP resistance include an impaired influx of CDDP, and activation of different multidrug mechanisms, including glutathione and multidrug-resistance associated protein (MRP) $[30,65]$. Alterations in sensitivity to specific cytotoxic agents, including increased resistance and sensitivity, were observed in many experimentally induced radioresistant cells [21, 22, 25, 27, 28, 30]. Increased level of ROS scavengers associated with cellular radioresistance can also reduce sensitivity to platinum drugs through neutralization of platinum-induced oxidative stress $[24,27,66]$. On the other hand, the isogenic radiosensitive cells were more sensitive to CDDP, Oxa, and BLM. Isogenic pairs of HPVpositive and HPV-negative cells have not been evaluated in terms of chemosensitivity and the available data on CDDP sensitivity of HPV-positive head and neck SCC is not conclusive. HPV-positive cells were found to be either CDDPresistant [67] or equally sensitive to CDDP compared to HPV-negative head and neck SCC [68].

The observed differences in DNA damage signaling gene expression in isogenic cells with different radiosensitivity indicate a role of several DNA damage signalling genes in the mechanisms of radioresistance. However, this should be further confirmed by quantitative and functional expression of specific proteins which is one of the future perspectives of this study. Identification of deregulated proteins could be applied clinically in terms of either radioresistance-associated biomarkers or as potential targets for radiosensitization. These novel biomarkers related to either radiosensitivity or radioresistance would permit improved stratification of HNSCC patients based on the predicted response to irradiation [69]. Radiosensitization of more radioresistant tumors could also lead to reduced total irradiation dose, fewer and/ or milder adverse effects. Dose de-escalation is a feasible approach for HPV-positive oropharyngeal HNSCC, with high response rate and reduced toxicity $[5,70,71]$.

\section{Conclusion}

This study showed that experimentally induced radioresistant cells are a suitable model to study the mechanisms of radioresistance conferring survival advantage. The experimentally induced radioresistance in our isogenic model is primarily associated with lower susceptibility to DNA damage, faster DNA repair and CDDP cross-resistance. The results were confirmed by both functional assays and transcriptomic analysis of DNA DSR genes. Furthermore, we identified several deregulated genes likely to play a role in the radioresistance and potential targets to achieve cellular radiosensitization. In addition, our results indicate a lack of adaptive response to irradiation in radiosensitive cells, possibly due to reduced ability to repair a high number of DNA DSBs via $\mathrm{HR}$ as demonstrated by immunofluorescence staining of $\gamma \mathrm{H} 2 \mathrm{AX}$ foci and differential gene expression in response to irradiation. To confirm their role in radioresistance, further experiments, beyond the scope of this study are needed. We propose targeting specific genes $X R C C 2, X R C C 3, H 2 A F X$, and GADD45A. In order to confirm their role in radiomodulation, enhancing their expression in radioresistant cells, or silencing them in radiosensitive or parental cells should be tested. Additionally, to avoid cross-resistance to CDDP in radioresistant cells enhancing expression of GADD45A or silencing of XPA could increase sensitivity to CDDP.

\section{Supplementary information}

Supplementary information accompanies this paper at https://doi.org/10. 1186/s13014-019-1418-6.

Additional file 1. Final report of laboratory examination.

Additional file 2. Final report of laboratory examination.

Additional file 3: Figure S1. Representative DNA content frequency histograms of (a) isogenic parental FaDu, (b) radioresistant FaDu-RR, and (c) radiosensitive $2 \mathrm{~A} 3$ cells before irradiation, $5 \mathrm{~h}$ and $24 \mathrm{~h}$ after $5 \mathrm{~Gy}$ irradiation.

Additional file 4: Figure S2. Representative images of flow cytometry detection of apoptosis by FITC Annexin V/7-AAD staining before irradiation, $5 \mathrm{~h}, 24 \mathrm{~h}, 48 \mathrm{~h}$ and $72 \mathrm{~h}$ after $5 \mathrm{~Gy}$ irradiation. Bottom left quadrant are viable (Annexin $\mathrm{V}$-negative and $7 \mathrm{AAD}$-negative) cells, bottom right quadrant are early apoptotic (Annexin V-positive and 7AADnegative) cells, top right quadrant are late apoptotic and/or necrotic (Annexin V-positive and 7AAD-positive) cells, and top left quadrant are necrotic (Annexin $V$-negative and 7AAD-positive) cells.

Additional file 5: Table S1. A list of genes included on $\mathrm{RT}^{2}$ Profiler $^{\mathrm{TM}}$ PCR Array Human DNA Damage Signaling Pathway (PAHS-029Z, Qiagen).

Additional file 6: Table S2. Radiosensitivity parameters describing survival advantage of isogenic head and neck SCC cells with different radiosensitivity.

Additional file 7: Figure S3. Changes in cell cycle phase distribution at different time points before and after 5 Gy irradiation in isogenic parental $\mathrm{FaDu}$, radioresistant FaDu-RR and radiosensitive $2 \mathrm{~A} 3$ cells. Symbols are mean values with sem from three independent experiments. * indicates significant difference in comparison to non-irradiated control cells; n.s. non-significant. 
Additional file 8: Table S3. Percentage of early and late apoptotic cells in control non-irradiated isogenic cells.

Additional file 9: Figure S4. Fold-induction of apoptosis in parental $\mathrm{FaDu}(\mathrm{a})$, radioresistant FaDu-RR (b) and radiosensitive $2 \mathrm{~A} 3$ cells (c) at different time points after $5 \mathrm{~Gy}$ irradiation. Symbols are mean values with sem from three independent experiments. ${ }^{*}$ indicates significant difference between control and 5 Gy-irradiated cells; ${ }^{* *}$ indicated significant difference between $5 \mathrm{~h}$ and $72 \mathrm{~h}$; \# indicates significantly increased foldinduction of apoptosis; n.s. - non-significant.

Additional file 10: Figure S5. Fold-change in cell viability of isogenic parental FaDu (a), radioresistant FaDu-RR (b) and radiosensitive $2 \mathrm{~A} 3$ cells (c) at different time points after 5 Gy irradiation. Symbols are mean values with sem from three independent experiments. ${ }^{* *}$ indicates significantly different fold-change of cell viability in comparison to non-irradiated cells and 5 Gy irradiated FaDu cells at earlier time points; ${ }^{*}$ indicates significantly different fold-change in cell viability between non-irradiated and 5 Gy irradiated FaDu-RR cells $72 \mathrm{~h}$ after irradiation; ** indicates significantly different fold-change of cell viability in comparison to non-irradiated and 5 Gy irradiated $2 \mathrm{~A} 3$ cells $5 \mathrm{~h}$ and $24 \mathrm{~h}$ after irradiation; \# indicates significantly different fold-change of cell viability in comparison to nonirradiated $2 A 3$ cells $24 h, 48 h$ and $72 h$.

Additional file 11: Figure S6. (a) Normalized nuclei area, (b) percent of enlarged nuclei, and (c) median number of $\mathrm{YH} 2 \mathrm{AX}$ foci/nuclei in parental FaDu, radioresistant FaDu-RR, and radiosensitive $2 \mathrm{~A} 3$ cells at various recovery times after $5 \mathrm{~Gy}$ irradiation. Box plots are median with 25th and 75th percentile with 10th and 90th percentiles as bottom and top whiskers. Bars are pooled data from three independent experiments. * indicates significantly enlarged normalized nuclei area compared to other groups.

Additional file 12: Figure S7. Functional analysis of DNA damage signalling and repair gene expression in non-irradiated isogenic cells. (a) Top 7 functions associated with the differentially expressed genes in radioresistant FaDu-RR cells. (b) Interactions between the differentially expressed genes in radioresistant FaDu-RR cells. (c) Top 7 functions associated with the differentially expressed genes in radiosensitive $2 \mathrm{~A} 3$ cells. (d) Interactions between the differentially expressed genes in radiosensitive $2 \mathrm{~A} 3$ cells. Functions of and interactions between the genes were visualized through GeneMANIA. Circles represent differentially expressed genes in comparison to non-irradiated parental FaDu cells. The colours within the circle represent specific functions associated with the specific gene. The coloured links between the genes represent the type of interaction between the differentially expressed genes. (e) Schematic diagram of differentially expressed genes involved in specific over-represented pathways of DNA repair, cell cycle and programmed cell death in nonirradiated radioresistant FaDu-RR (green box) and radiosensitive 2A3 cells (blue box). Genes in bold are differentially expressed in both radioresistant FaDu-RR and radiosensitive 2A3 cells. An upward pointing arrow indicates over-expression, a downward pointing arrow indicates underexpression of a specific gene. A schematic diagram is adapted from Reactome Pathway Database.

Additional file 13: Figure S8. Functional analysis of DNA damage signalling and repair gene expression in irradiated isogenic cells. (a) Top 7 functions associated with the differentially expressed genes in 5 Gyirradiated parental FaDu cells. (b) Interactions between the differentially expressed genes in 5 Gy-irradiated parental FaDu cells. (c) Top 7 functions associated with the differentially expressed genes in 5 Gy-irradiated radioresistant $\mathrm{FaDu}$-RR cells. (d) Interactions between the differentially expressed genes in 5 Gy-irradiated radioresistant FaDu-RR cells. Functions of and interactions between the genes were visualized through GeneMANIA. Circles represent differentially expressed genes in 5 Gy-irradiated cells relative to pertinent non-irradiated cells. The colors within the circle represent specific functions associated with the specific gene. The colored links between the genes represent the type of interaction between the differentially expressed genes. (e) Schematic diagram of differentially expressed genes involved in specific pathways of DNA repair, cell cycle and programmed cell death in 5 Gy-irradiated parental FaDu (light blue box), radioresistant FaDu-RR (green box) and radiosensitive $2 \mathrm{~A} 3$ cells (blue box). Genes in bold are differentially expressed in both parental FaDu and radioresistant FaDu-RR cells. An upward pointing arrow indicates over-expression; a downward pointing arrow indicates under-expression of a specific gene. A schematic diagram is adapted from Reactome Pathway Database.

Additional file 14: Figure S9. Functional analysis of DNA damage signalling and repair gene expression in irradiated isogenic cells. (a) Top 7 functions associated with the differentially expressed genes in $5 \mathrm{~Gy}$ irradiated radioresistant FaDu-RR cells. (b) Interactions between the differentially expressed genes in 5 Gy-irradiated radioresistant FaDu-RR cells. (c) Top 7 functions associated with the differentially expressed genes in 5 Gy-irradiated radiosensitive $2 \mathrm{~A} 3$ cells. (d) Interactions between the differentially expressed genes in $5 \mathrm{~Gy}$-irradiated radiosensitive $2 \mathrm{~A} 3$ cells. Functions of and interactions between the genes were visualized through GeneMANIA. Circles represent differentially expressed genes in comparison to 5 Gy-irradiated parental FaDu cells. Colours within the circle represent specific functions associated with the specific gene. The coloured links between the genes represent the type of interaction between the differentially expressed genes. (e) Schematic diagram of differentially expressed genes involved in specific pathways of DNA repair, cell cycle and programmed cell death in 5 Gy-irradiated radioresistant FaDu-RR (green box) and radiosensitive 2A3 cells (blue box). Genes in bold are differentially expressed in both radioresistant FaDu-RR and radiosensitive $2 \mathrm{~A} 3$ cells. An upward pointing arrow indicates over-expression, a downward pointing arrow indicates under-expression of a specific gene. A schematic diagram is adapted from Reactome Pathway Database.

\section{Abbreviations}

AM: Arithmetic mean; BER: Base excision repair; BLM: Bleomycin; CDDP: Cisplatin; $D_{10}$ : Dose required to kill $90 \%$ of the cells; DMF: Dosemodifying factor; DSB: Double-strand break; DSR: Damage signalling and repair; DT: Doubling time; $\mathrm{ED}_{50}$ : Effective dose killing $50 \%$ of the cells; HPV: Human papillomavirus; HR: Homologous recombination; $I_{50}$ : Halfmaximal inhibitory concentration; LQ: Linear-quadratic model; NER: Nucleotide excision repair; NHEJ: Non-homologous end-joining; Oxa: Oxaliplatin; ROS: Reactive oxygen species; RT-PCR: Real time reverse transcription polymerase chain reaction; SCC: Squamous cell carcinoma; SEM: Standard error of the mean; SF2: Surviving fraction at 2 Gy

\section{Acknowledgements}

We would like to thank Ilija Vojvodic for technical support on radiation and Simon Bucek for help with flow cytometry.

\section{Authors' contributions}

VT - Conceptualization, formal analysis, investigation, methodology, project administration, supervision, visualization, writing - original draft preparation, writing - review and editing. AP - Formal analysis, investigation. MNZ Formal analysis, investigation. MS - Investigation, methodology, writing — review and editing. AB - Formal analysis, investigation. BG - Formal analysis, methodology, writing - review and editing. PS - Conceptualization, funding acquisition, resources, writing — review and editing. MC Conceptualization, funding acquisition, resources, writing - review and editing. GS - Conceptualization, funding acquisition, resources, writing - review and editing. All authors read and approved the final manuscript.

\section{Funding}

This work was supported by the Slovenian Research Agency (program no. P3-0003, and P3-0307, project no. J3-7460).

\section{Availability of data and materials}

The datasets during and/or analysed during the current study available from the corresponding author on reasonable request.

\section{Ethics approval and consent to participate}

Not applicable.

\section{Consent for publication}

Not applicable.

\section{Competing interests}

The authors declare that they have no competing interests. 


\section{Author details}

'Department of Experimental Oncology, Institute of Oncology Ljubljana, Ljubljana, Slovenia. ${ }^{2}$ Department of Cytopathology, Institute of Oncology Ljubljana, Ljubljana, Slovenia. ${ }^{3}$ Department of Radiation Oncology, Institute of Oncology Ljubljana, Ljubljana, Slovenia. ${ }^{4}$ University of Ljubljana, Faculty of Medicine, Ljubljana, Slovenia. ${ }^{5}$ University of Primorska, Faculty of Health Sciences, Izola, Slovenia. ${ }^{6}$ University of Ljubljana, Faculty of Health Sciences, Ljubljana, Slovenia.

Received: 14 June 2019 Accepted: 11 November 2019 Published online: 27 November 2019

\section{References}

1. Vigneswaran N, Williams MD. Epidemiologic trends in head and neck Cancer and aids in diagnosis. Oral Maxillofac Surg Clin Nort Am. 2014;26(2):123-41.

2. Marur S, Forastiere AA. Head and neck squamous cell carcinoma: update on epidemiology, diagnosis, and treatment. Mayo Clin Proc. 2016;91(3):386-96.

3. Arenz A, Ziemann F, Mayer C, Wittig A, Dreffke K, Preising S, et al. Increased radiosensitivity of HPV-positive head and neck cancer cell lines due to cell cycle dysregulation and induction of apoptosis. Strahlentherapie und Onkol. 2014;190(9):839-46.

4. Rieckmann T, Tribius S, Grob TJ, Meyer F, Busch C-JJ, Petersen C, et al. HNSCC cell lines positive for HPV and p16 possess higher cellular radiosensitivity due to an impaired DSB repair capacity. Radiother Oncol. 2013;107(2):242-6.

5. Prevc A, Kranjc S, Cemazar M, Todorovic V, Zegura B, Novak M, et al. DoseModifying Factor of Radiation Therapy with Concurrent Cisplatin Treatment in HPV-Positive Squamous Cell Carcinoma: A Preclinical Study. Radiat Res. 2018;189(6):1-8.

6. Pignon JP, le Maître A, Maillard E, Bourhis J. Meta-analysis of chemotherapy in head and neck cancer (MACH-NC): an update on 93 randomised trials and 17,346 patients. Radiother Oncol. 2009;92(1):4-14.

7. Strojan P, Corry J, Eisbruch A, Vermorken JB, Mendenhall WM, Lee AWM, et al. Recurrent and second primary squamous cell carcinoma of the head and neck: when and how to reirradiate. Head Neck. 2015;37(1):134-50.

8. Blanchard P, Baujat B, Holostenco V, Bourredjem A, Baey C, Bourhis J, et al. Meta-analysis of chemotherapy in head and neck cancer (MACH-NC): a comprehensive analysis by tumour site. Radiother Oncol. 2011;100(1):33-40.

9. McDermott N, Meunier A, Lynch TH, Hollywood D, Marignol L. Isogenic radiation resistant cell lines: development and validation strategies. Int J Radiat Biol. 2014;90(2):115-26.

10. Kuwahara $Y$, Roudkenar MH, Urushihara $Y$, Saito $Y$, Tomita $K$, Roushandeh AM, et al. Clinically relevant radioresistant cell line: a simple model to understand cancer radioresistance. Med Mol Morphol. 2017:50(4):195-204.

11. Michna A, Schötz U, Selmansberger M, Zitzelsberger H, Lauber K, Unger K, et al. Transcriptomic analyses of the radiation response in head and neck squamous cell carcinoma subclones with different radiation sensitivity: timecourse gene expression profiles and gene association networks. Radiat Oncol. 2016;11(1):94.

12. Harris M, Wang XG, Jiang Z, Goldberg GL, Casadevall A, Dadachova E. Radioimmunotherapy of experimental head and neck squamous cell carcinoma (HNSCC) with E6-specific antibody using a novel HPV-16 positive HNSCC cell line. Head Neck Oncol. 2011;3(1):9.

13. Otto F. DAPI staining of fixed cells for high-resolution flow cytometry of nuclear DNA. Methods Cell Biol. 1990;33:105-10.

14. Pogacnik A, Us-Krasovec M, Bracko M. Preparation of fine needle aspiration biopsy samples for flow cytometric analysis. Anal Quant Cytol Histol. 1993; 15(4):298-302.

15. Zakelj MNMN, Prevc A, Kranjc S, Cemazar M, Todorovic V, Savarin M, et al. Electrochemotherapy of radioresistant head and neck squamous cell carcinoma cells and tumor xenografts. Oncol Rep. 2019;41(3):1658-68.

16. Siddiqui MS, François $M$, Fenech MF, Leifert WR. Persistent $\mathrm{YH} 2 \mathrm{AX}$ : a promising molecular marker of DNA damage and aging. Mutat Res - Rev Mutat Res. 2015;766:1-19.

17. Warde-Farley D, Donaldson SL, Comes O, Zuberi K, Badrawi R, Chao P, et al. The GeneMANIA prediction server: biological network integration for gene prioritization and predicting gene function. Nucleic Acids Res. 2010; 38(SUPPL. 2):214-20

18. Fabregat A, Jupe S, Matthews L, Sidiropoulos K, Gillespie M, Garapati P, et al. The Reactome pathway knowledgebase. Nucleic Acids Res. 2018; 46(D1):D649-55.
19. Kurth I, Hein L, Mäbert K, Peitzsch C, Koi L, Cojoc M, et al. Cancer stem cell related markers of radioresistance in head and neck squamous cell carcinoma. Oncotarget. 2015;6(33):34494-509.

20. Skvortsov $S$, Jimenez CR, Knol JC, Eichberger $P$, Schiestl B, Debbage $P$, et al. Radioresistant head and neck squamous cell carcinoma cells: intracellular signaling, putative biomarkers for tumor recurrences and possible therapeutic targets. Radiother Oncol. 2011;101(1):177-82.

21. Skvortsov S, Dudás J, Eichberger P, Witsch-Baumgartner M, Loeffler-Ragg J, Pritz C, et al. Rac1 as a potential therapeutic target for chemo-radioresistant head and neck squamous cell carcinomas (HNSCC). Br J Cancer. 2014; 110(11):2677-87.

22. Xie L, Song $X$, Yu J, Wei L, Song B, Wang $X$, et al. Fractionated irradiation induced radio-resistant esophageal cancer EC109 cells seem to be more sensitive to chemotherapeutic drugs. J Exp Clin Cancer Res. 2009;28:68.

23. De Llobet LI, Baro M, Figueras A, Modolell I, Da Silva MV, Muñoz P, et al. Development and characterization of an isogenic cell line with a radioresistant phenotype. Clin Transl Oncol. 2013;15(3):189-97.

24. Lin TY, Chang JTC, Wang HM, Chan SH, Chiu CC, Lin CY, et al. Proteomics of the radioresistant phenotype in head-and-neck cancer: GP96 as a novel prediction marker and sensitizing target for radiotherapy. Int J Radiat Oncol Biol Phys. 2010;78(1):246-56.

25. McDermott N, Meunier A, Mooney B, Nortey G, Hernandez C, Hurley S, et al. Fractionated radiation exposure amplifies the radioresistant nature of prostate cancer cells. Sci Rep. 2016;6(October):34796.

26. Skvortsova I, Skvortsov S, Stasyk T, Raju U, Popper B-A, Schiestl B, et al. Intracellular signaling pathways regulating radioresistance of human prostate carcinoma cells. Proteomics. 2008;8(21):4521-33.

27. Lee YS, Oh JH, Yoon S, Kwon MS, Song CW, Kim KH, et al. Differential gene expression profiles of Radioresistant non-small-cell lung Cancer cell lines established by fractionated irradiation: tumor protein p53-inducible protein 3 confers sensitivity to ionizing radiation. Int J Radiat Oncol Biol Phys. 2010;77(3):858-66.

28. Wei QC, Shen L, Zheng S, Zhu YL. Isolation and characterization of radiationresistant lung cancer D6-R cell line. Biomed Environ Sci. 2008;21(4):339-44.

29. Ogawa K, Utsunomiya T, Mimori K, Tanaka F, Haraguchi N, Inoue H, et al. Differential gene expression profiles of radioresistant pancreatic cancer cell lines established by fractionated irradiation. Int J Oncol. 2006;28(3):705-13.

30. Harvie RM, Davey MW, Davey RA. Increased MRP expression is associated with resistance to radiation, anthracyclines and etoposide in cells treated with fractionated ??-radiation. Int J Cancer. 1997;73(1):164-7.

31. Gray M, Turnbull AK, Ward C, Meehan J, Martínez-Pérez C, Bonello M, et al. Development and characterisation of acquired radioresistant breast cancer cell lines. Radiat Oncol. 2019;14(1):1-19.

32. Kuwahara Y, Li L, Baba T, Nakagawa H, Shimura T, Yamamoto Y, et al. Clinically relevant radioresistant cells efficiently repair DNA double-strand breaks induced by X-rays. Cancer Sci. 2009;100(4):747-52.

33. Pearce AG, Segura TM, Rintala AC, Rintala-maki ND, Lee $H$. The generation and characterization of a radiation-resistant model system to study Radioresistance in human breast Cancer cells. Radiat Res. 2001;750(6):739-50.

34. Lee SY, Park HR, Cho NH, Choi YP, Rha SY, Park SW, et al. Identifying genes related to radiation resistance in oral squamous cell carcinoma cell lines. Int J Oral Maxillofac Surg. 2013;42(2):169-76.

35. Yanagisawa T, Urade M, Takahashi Y, Kishimoto H, Sakurai K. Isolation and characterisation of radioresistant human KB carcinoma cells in vitro. Oral Oncol. 1998;34(1):30-8.

36. Henness S, Davey MW, Harvie RM, Davey RA. Fractionated irradiation of H69 small-cell lung cancer cells causes stable radiation and drug resistance with increased MRP1, MRP2, and topoisomerase llalpha expression. Int J Radiat Oncol Biol Phys. 2002;54(3):895-902.

37. Fukuda K, Sakakura C, Miyagawa K, Kuriu Y, Kin S, Nakase Y, et al. Differential gene expression profiles of radioresistant oesophageal cancer cell lines established by continuous fractionated irradiation. 2004:91;1543-50.

38. Borràs-Fresneda M, Barquinero JF, Gomolka M, Hornhardt S, Rössler U, Armengol $G$, et al. Differences in DNA repair capacity, cell death and transcriptional response after irradiation between a radiosensitive and a Radioresistant cell line. Sci Rep. 2016;6:1-11.

39. Thomas M, Banks L. Human papillomavirus (HPV) E6 interactions with Bak are conserved amongst E6 proteins from high and low risk HPV types. J Gen Virol. 1999:80(6):1513-7.

40. TO G, Filippova M, Duerksen-Hughes PJ. Accelerated degradation of FADD and procaspase 8 in cells expressing human papilloma virus 16 E6 impairs TRAIL-mediated apoptosis. Cell Death Differ. 2006;13(11):1915-26. 
41. Rothkamm K, Lobrich M. Evidence for a lack of DNA double-strand break repair in human cells exposed to very low $x$-ray doses. Proc Natl Acad Sci. 2003;100(9):5057-62.

42. Marullo R, Werner E, Zhang H, Chen GZ, Shin DM, Doetsch PW. HPV16 E6 and E7 proteins induce a chronic oxidative stress response via NOX2 that causes genomic instability and increased susceptibility to DNA damage in head and neck cancer cells. Carcinogenesis. 2015;36(11):1397-406.

43. Borràs $M$, Armengol $G$, De Cabo M, Barquinero JF, Barrios L. Comparison of methods to quantify histone $\mathrm{H} 2 \mathrm{AX}$ phosphorylation and its usefulness for prediction of radiosensitivity. Int J Radiat Biol. 2015;91(12):915-24.

44. Lynam-Lennon N, Reynolds JV, Pidgeon GP, Lysaght J, Marignol L, Maher $\mathrm{SG}$. Alterations in DNA repair efficiency are involved in the Radioresistance of esophageal adenocarcinoma. Radiat Res. 2010;174(6a):703-11.

45. Morgan MA, Lawrence TS. Molecular pathways: overcoming radiation resistance by targeting DNA damage response pathways. Clin Cancer Res. 2015;21(13):2898-904.

46. Olive PL, Banáth JP. Phosphorylation of histone H2AX as a measure of radiosensitivity. Int J Radiat Oncol Biol Phys. 2004;58(2):331-5.

47. Vargas-Rondón N, Villegas VE, Rondón-Lagos M. The Role of Chromosomal Instability in Cancer and Therapeutic Responses. Cancers (Basel). 2017;10(1): $1-21$.

48. Mladenov E, Magin S, Soni A, Iliakis G. DNA double-strand break repair as determinant of cellular radiosensitivity to killing and target in radiation therapy. Front Oncol. 2013;3:113.

49. Guo W-F, Lin R-X, Huang J, Zhou Z, Yang J, Guo G, et al. Identification of differentially expressed genes contributing to radioresistance in lung cancer cells using microarray analysis. Radiat Res. 2005;164(1):27-35.

50. Nalepa G, Clapp DW. Fanconi anaemia and cancer: an intricate relationship. Nat Rev Cancer. 2018;18(3):168-85.

51. Spriggs CC, Laimins LA. FANCD2 Binds Human Papillomavirus Genomes and Associates with a Distinct Set of DNA Repair Proteins to Regulate Viral Replication. MBio. 2017:8(1):1-19.

52. Rosemary Siafakas A, Richardson DR. Growth arrest and DNA damage-45 alpha (GADD45a). Int J Biochem Cell Biol. 2009;41(5):986-9.

53. Barreto G, Schäfer A, Swaminathan SK, Döderlein G, Maltry N, Stach D, et al. Gadd45a promotes epigenetic gene activation by repair-mediated DNA demethylation. Nature. 2007;445(7128):671-5.

54. Wang BX, Yin BL, He B, Chen C, Zhao M, Zhang WX, et al. Overexpression of DNA damage-induced 45 a gene contributes to esophageal squamous cell cancer by promoter hypomethylation. J Exp Clin Cancer Res. 2012;31(11):1-13.

55. Zhang X, Wei F, Zhou C, Sun S, Qu X, Wang C, et al. Over-expression of Gadd45a enhances radiotherapy efficacy in human Tca8113 cell line. Acta Pharmacol Sin. 2011;32(2):253-8.

56. Liu J, Jiang G, Mao P, Zhang J, Zhang L, Liu L, et al. Down-regulation of GADD45A enhances chemosensitivity in melanoma. Sci Rep. 2018;8(1):4111.

57. Yan SJ, Lee YF, Ting HJ, Liu NC, Liu S, Lin SJ, et al. Deficiency in TR4 nuclear receptor abrogates Gadd45a expression and increases cytotoxicity induced by ionizing radiation. Cell Mol Biol Lett. 2012;17(2):309-22.

58. Weyemi U, Redon CE, Choudhuri R, Aziz T, Maeda D, Boufraqech M, et al. The histone variant H2A.X is a regulator of the epithelial-mesenchymal transition. Nat Commun. 2016;7:1-12.

59. Tambini CE, Spink KG, Ross CJ, Hill MA, Thacker J. The importance of XRCC2 in RAD51-related DNA damage repair. DNA Repair (Amst). 2010;9(5):517-25.

60. Wang Q, Wang Y, Du L, Xu C, Sun Y, Yang B, et al. Shrna-mediated XRCC2 gene knockdown efficiently sensitizes colon tumor cells to $X$-ray irradiation in vitro and in vivo. Int J Mol Sci. 2014;15(2):2157-71.

61. Saxena S, Somyajit K, Nagaraju G. XRCC2 Regulates Replication Fork Progression during dNTP Alterations. Cell Rep. 2018;25(12):3273-3282.e6.

62. Cheng J, Liu W, Zeng X, Zhang B, Guo Y, Qiu M, et al. XRCC3 is a promising target to improve the radiotherapy effect of esophageal squamous cell carcinoma. Cancer Sci. 2015;106(12):1678-86

63. Wang D, Lippard SJ. Cellular processing of platinum anticancer drugs. Nat Rev Drug Deliv. 2005:4(4):307-20.

64. Sun C, Wang Z, Song W, Chen B, Zhang J, Dai X, et al. Alteration of DNA damage signaling pathway profile in radiation-treated glioblastoma stemlike cells. Oncol Lett. 2015;10(3):1769-74.

65. Shen D-W, Pouliot LM, Hall MD, Gottesman MM. Cisplatin resistance: a cellular self-defense mechanism resulting from multiple epigenetic and genetic changes. Pharmacol Rev. 2012;64(3):706-21.
66. Fong CW. Platinum anti-cancer drugs: free radical mechanism of PtDNA adduct formation and anti-neoplastic effect. Free Radic Biol Med. 2016;95:216-29.

67. Nagel R, Martens-de Kemp SR, Buijze M, Jacobs G, Braakhuis BJM, Brakenhoff $\mathrm{RH}$. Treatment response of HPV-positive and HPV-negative head and neck squamous cell carcinoma cell lines. Oral Oncol. 2013;49(6):560-6.

68. Busch C-J, Becker B, Kriegs M, Gatzemeier F, Krüger K, Möckelmann N, et al. Similar cisplatin sensitivity of HPV-positive and -negative HNSCC cell lines. Oncotarget. 2016;7(24):35832-42.

69. Pardo-Reoyo S, Roig-Lopez JL, Yang ES. Potential biomarkers for radiosensitivity in head and neck cancers. Ann Transl Med. 2016:4(24):524.

70. Wierzbicka M, Szyfter K, Milecki P, Składowski K, Ramlau R. The rationale for HPV-related oropharyngeal cancer de-escalation treatment strategies. Contemp Oncol (Poznan). 2015;19(4):313-22.

71. Kimple RJ, Harari PM. Is radiation dose reduction the right answer for HPVpositive head and neck cancer? Oral Oncol. 2014;50(6):560-4.

\section{Publisher's Note}

Springer Nature remains neutral with regard to jurisdictional claims in published maps and institutional affiliations.
Ready to submit your research? Choose BMC and benefit from:

- fast, convenient online submission

- thorough peer review by experienced researchers in your field

- rapid publication on acceptance

- support for research data, including large and complex data types

- gold Open Access which fosters wider collaboration and increased citations

- maximum visibility for your research: over $100 \mathrm{M}$ website views per year

At $\mathrm{BMC}$, research is always in progress.

Learn more biomedcentral.com/submissions 